\title{
TEMPERATURE COEFFICIENT OF THE MODULI OF METALS AND ALLOYS USED AS ELASTIC ELEMENTS
}

\author{
By G. H. Keulegan and M. R. Houseman
}

\section{ABSTRACT}

In continuation of the work reported in N. A. C. A. Technical Report No. 358, the temperature coefficients of the modulus of rigidity and of Young's modulus of elasticity of 31 alloys and metals have been determined in the temperature range $-50^{\circ}$ to $+50^{\circ} \mathrm{C}$. These were selected on the basis of their possible use as elastic elements for aircraft and other instruments. In most cases the temperature coefficients were determined with the metal in the condition of heat treatment or cold work most suitable for its use as an elastic element and also in the annealed condition. The coefficient of each modulus at $0^{\circ} \mathrm{C}$., the ratio of the coefficient at $+25^{\circ}$ to that at $-25^{\circ} \mathrm{C}$., the composition and the heat treatment or cold work are given for each sample. The temperature coefficient of Poisson's ratio and the significance of the differences in the two coefficients for a given material are discussed.

\section{CONTENTS}

Page

290

290

290

290

(a) Derivation of the working formula

(b) The effect of elastic afterworking and permanent set in the springs.

2. Description of apparatus

(a) Apparatus principally used

(b) Apparatus for testing small springs ...........

3. Materials

(a) Chemical composition

(b) Form and dimensions of springs

(c) Heat treatment and hardness

4. Experimental procedure and results

(a) Experimental procedure

(b) Corrections applied to the readings

(c) Method of reducing the data

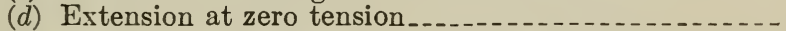

(e) Experimental results....

(f) Accuracy of results

III. Temperature coefficient of Young's modulus of elasticity

1. Derivation of the working formula

2. Description of the apparatus.

3. Materials

4. Experimental procedure and results

(a) Experimental procedure.........

(b) Method of reducing the data

(c) Effect of temperature at initial zero angular deflection -

(d) Experimental results

(e) Accuracy of results

IV. Discussion

1. Anomalous behavior of stainless steel

2. Relative values of the temperature coefficients

3. Variation of the temperature coefficients of the moduli with temperature.

4. Temperature coefficient of Poisson's ratio

5. Effect of heat treatment on the temperature coefficients of the elastic moduli. 


\section{INTRODUCTION}

This investigation is an extension of that made by Brombacher and Melton, ${ }^{1}$ and was made with the financial support and cooperation of the National Advisory Committee for Aeronautics.

In order that the performance of aircraft instruments be considered satisfactory their indications should be independent of temperature in approximately the range $-50^{\circ}$ to $+50^{\circ} \mathrm{C}$. The effect of temperature on instruments of correct mechanical design is due largely to the change in the elastic moduli with temperature of the elastic elements used. Among these elements are the diaphragm capsules and springs of pressure-measuring instruments, the springs of accelerometers and tachometers, and the hair springs of electrical instruments. Data on the temperature coefficients of the elastic moduli are of primary value.

This investigation was undertaken: $(a)$ To measure, in the temperature range $-50^{\circ}$ to $+50^{\circ} \mathrm{C}$., the temperature coefficients of both the modulus of rigidity and Young's modulus of elasticity of various metals and alloys of possible use for diaphragms and springs, including materials having small (or anomalous) temperature coefficients. (b) To determine the effect on the temperature coefficients of annealing, cold working, or tempering the materials.

Brombacher and Melton used a torsion pendulum to determine the temperature coefficient of the modulus of rigidity and the effect of stress and heat treatment on both the modulus and the temperature coefficient. This method has serious disadvantages. In selecting a more suitable experimental method consideration was given to the practical necessity of obtaining temperature control by means of a liquid bath and to the desirable possibility of obtaining the data on both moduli from the same specimen of a given material. This led to the use of helical spring specimens. Two springs of the given material and of the same design were coupled together and $(a)$ stressed in tension to obtain the temperature coefficient of the rigidity modulus and $(b)$ stressed in twist to obtain the temperature coefficient of Young's modulus of elasticity. While under each type of stress the change in the deformation of the springs of the coupled system was measured as the temperature of one of the springs was varied while that of the other spring was maintained constant. The use of two springs was necessary to eliminate lateral vibration and to a large extent the effect of elastic afterworking or drift. If the two springs were exactly alike the drift would not change the deflection of the springs since their actions opposed each other.

\section{TEMPERATURE COEFFICIENT OF THE MODULUS OF RIGIDITY}

\section{THEORY}

(a) DERIVATION OF THE WORKING FORMULA

Consider an ideal arrangement of the parts of the apparatus used to determine the temperature coefficient of rigidity as shown diagrammatically in Figure 1. Two helical springs $s_{1}$ and $s_{2}$, similar in construction and material, are attached to a base $B B$ by means of the

1 W. G. Brombacher and E. R. Melton, N. A. C. A. Technical Report No. 358, 1930. 
links $a_{1}$ and $a_{2}$. Spring $s_{2}$ is the test spring and spring $s_{1}$ the auxiliary spring. During a test the temperature of the test spring is varied while that of the auxiliary spring is kept constant. The upper ends of these springs are connected to the ends of a horizontal lever $P_{1}, P_{2}$ by means of the connecting links $b_{1}$ and $b_{2}$. The center of the lever rests on a support $E$ which is adjustable in length. Each spring is immersed in a liquid temperature bath.

When both springs are at the temperature $\theta_{1}$ we denote their stiffnesses by $S_{1}$ and $S_{2}$. When the length of $E$ is so adjusted that the springs are not stressed the heights of $P_{1}$ and $P_{2}$ above a fixed reference plane are $X_{10}$ and $X_{20}$. With both springs at the same temperature $\theta_{1}$ the auxiliary and test springs are deflected by increasing the length of $E$ until the heights of $P_{1}$ and $P_{2}$ above the reference plane are $X_{1}$ and $X_{2}$. Since the spring reactions are equal in magnitude, we have

$$
\left(X_{1}-X_{10}\right) S_{1}=\left(X_{2}-X_{20}\right) S_{2}
$$

If now the temperature of the bath surrounding the test spring is increased by a small amount, the temperature of the bath surrounding

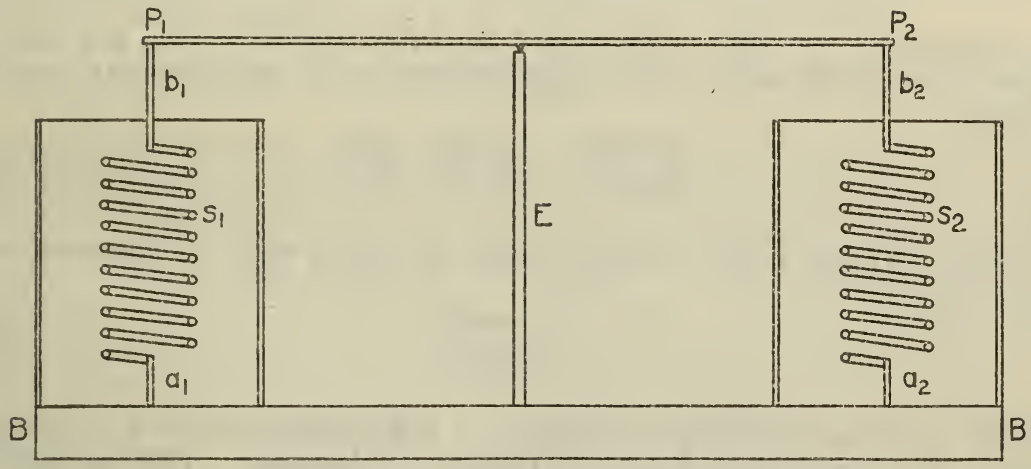

FIGURE 1.-Simplified diagram of the apparatus for the determination of the temperature coefficient of the rigidity modulus

the auxiliary spring being kept constant, the deflections $X_{1}$ and $X_{2}$ are altered, the stiffness $S_{2}$ is modified and, because of the thermal expansion of the spring and the connecting links $a_{2}$ and $b_{2}$, the position of zero stress in the springs will also be changed. The rate of change may be determined by differentiating equation (1) with respect to temperature. We thus obtain

$$
S_{2}\left(\begin{array}{c}
d X_{2} \\
d \theta
\end{array}-\frac{d X_{20}}{d \theta}\right)+\left(X_{2}-X_{20}\right) \frac{d S_{2}}{d \theta}=S_{1}\left(\frac{d X_{1}}{d \theta}-\frac{d X_{10}}{d \theta}\right)
$$

Since the springs are coupled together in opposition

$$
\frac{d X_{1}}{d \theta}=-\frac{d X_{2}}{d \theta} \text { and } \frac{d X_{10}}{d \theta}=-\frac{d X_{20}}{d \theta}
$$

whence

$$
\left(S_{1}+S_{2}\right)\left(\frac{d X_{2}}{d \theta}-\frac{d X_{20}}{d \theta}\right)=-\left(X_{2}-X_{20}\right) \frac{d S_{2}}{d \theta}
$$


But from equation (1)

$$
S_{1}=\frac{S_{2}\left(X_{2}-X_{20}\right)}{X_{1}-X_{10}}
$$

Introducing this expression into equation (2) we find

$$
\frac{1}{S_{2}} \frac{d S_{2}}{d \theta}=-\left(\frac{1}{X_{1}-X_{10}}+\frac{1}{X_{2}-X_{20}}\right)\left(\frac{d X_{2}}{d \theta}-\frac{d X_{20}}{d \theta}\right)
$$

It is clear, since $S_{1}$ does not appear in this equation, that it is not necessary that the temperatures of the two springs be initially the same, but it is essential that the auxiliary spring be kept at a constant temperature. In the experiments to be described, the change in $X_{2}$ was measured, starting from the condition when the temperature of the test springs was $+50^{\circ} \mathrm{C}$. Changes in $X_{2}$ and $X_{20}$ thus measured are denoted by $x$ and $x_{0}$, respectively. It is obvious that

$$
\frac{d X_{2}}{d \theta}=\frac{d x}{d \theta} \text { and } \frac{d X_{20}}{d \theta}=\frac{d x_{0}}{d \theta}
$$

Furthermore, in each experiment $X_{1}-\dot{X}_{10}$ and $X_{2}-X_{20}$ are nearly equal, and if we denote their mean value by $X$, equation (3) may be written

$$
\frac{1}{S_{2}} \frac{d S_{2}}{d \theta}=-\frac{2}{X}\left(\frac{d x}{d \theta}-\frac{d x_{0}}{d \theta}\right)
$$

The stiffness $S$ of a helical spring of round wire in terms of the constants is

$$
S=\frac{\pi r^{4} G}{2 R^{2} L}
$$

where $G$ is the modulus of rigidity, $r$ the radius of the wire, $R$ the radius of the coils, and $L$ the total length of the wire. This expression can also be written

$$
S=K L G
$$

where $K$ is a numerical constant of the spring and $L$ has the dimensions of length. $K$ is not affected by temperature if the ratios of $r / R$ and $r / L$ remain unaltered with temperature.

If equation (6) be differentiated with respect to $\theta$ and the result be divided by equation (6), we obtain

$$
\frac{1}{S} \frac{d S}{d \theta}=\alpha+\frac{1}{G} \frac{d G}{d \theta}
$$

$\alpha$ being the thermal coefficient of linear expansion. Introducing this in equation (4) there results

$$
\frac{1}{G} \frac{d G}{d \theta}=-\frac{2}{X}\left(\frac{d x}{d \theta}-\frac{d x_{0}}{d \theta}\right)-\alpha
$$

We place

$$
\bar{G} \frac{d G}{d \theta}=m
$$


Equation (7) is the working formula for the experiments. The term $m$ is by definition the temperature coefficient of the rigidity modulus. The quantity $\frac{d x}{d \theta}$ is the rate of change of the deflection of the test spring with temperature and is a function of the temperature and of the deflection $X_{2}-X_{20}$. It is determined graphically from the experimentally determined curves of $x$ as a function of the temperature for different initial deflections.

The quantity $\frac{d x_{0}}{d \theta}$ is the rate of change of the deflection of the spring with temperature at zero initial deflection; that is, for the spring in the initially unstressed condition. If it were not for the anomalous effects of internal stresses in the spring, $\frac{d x_{0}}{d \theta}$ could be computed from the thermal expansion of parts of the apparatus and of the spring. In the method actually adopted and known to be more reliable, $\frac{d x}{d \theta}$ is determined for several deflections and the data graphically extrapolated to zero deflection. This extrapolation involves the reasonable assumption that $X_{20}$ is independent of the deflection of the spring.

(b) THE EFFECT OF ELASTIC AFTERWORKING AND PERMANENT SET IN THE SPRINGS

Consideration must also be given to the effect of elastic afterworking and permanent set, since when these two effects are present, the stiffness of the springs at a given temperature is no longer constant as has been assumed in deriving the working formula given in the preceding section. The stiffness will then depend to a small degree upon the deflection and the duration of the deflection. Both the elastic afterworking and permanent set are increases in deflection with time while the load is maintained constant but differ in that, when the load is removed, the excess deflection is recovered only in the case of elastic afterworking.

The effect of permanent set and elastic afterworking were minimized by the experimental method adopted. Only the differential amount of these quantities for the two springs has an effect, as long as the actual amount of the set or elastic afterworking is of the second order compared with the deflections $X_{1}$ and $X_{2}$. The differential amount was kept small by using springs of the same material and of similar design. However, it was necessary to determine whether or not the effect was excessive in individual cases. For this purpose a theoretical analysis was made which showed that the change in the observed deflection due to elastic afterworking is at its maximum at the completion of the temperature cycle. Therefore, it is only necessary to note the difference between the initial reading and the final reading at the instant of completing the cycle, which if negligible, proves that the elastic afterworking is negligible. It is further evident that this difference also included the differential permanent set and thus this single criterion is sufficient for both if the difference is negligible. 


\section{DESCRIPTION OF APPARATUS}

\section{(a) APPARATUS PRINCIPALLY USED}

The apparatus used for the measurement of the temperature coefficient of the rigidity modulus is shown in Figures 2 and 3 . The bath for controlling the temperature of the springs $s_{1}$ and $s_{2}$ is con-

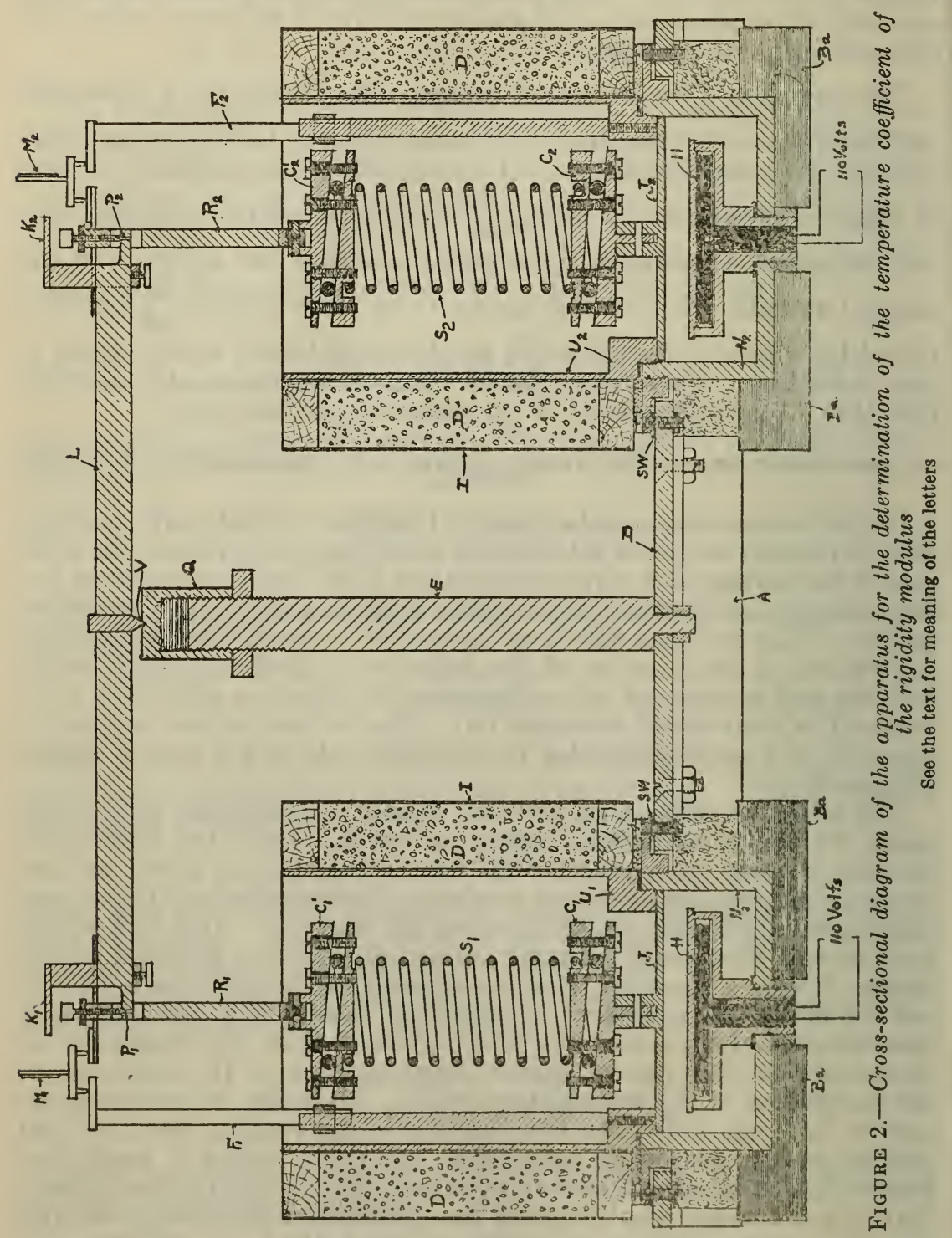

tained in the vessels formed by the removable cylinders $U_{1}$ and $U_{2}$ and the cups $N_{1}$ and $N_{2}$ which are permanently fastened to the base $B$. The springs are supported at their lower ends by slotted steel bars $J_{1}$ and $J_{2}$ which are attached to the heavy rings forming the lower end of $U_{1}$ and $U_{2}$. Similar clamps $C_{1}$ and $C_{2}$ are attached to each end of 
B. S. Journal of Research, RP531

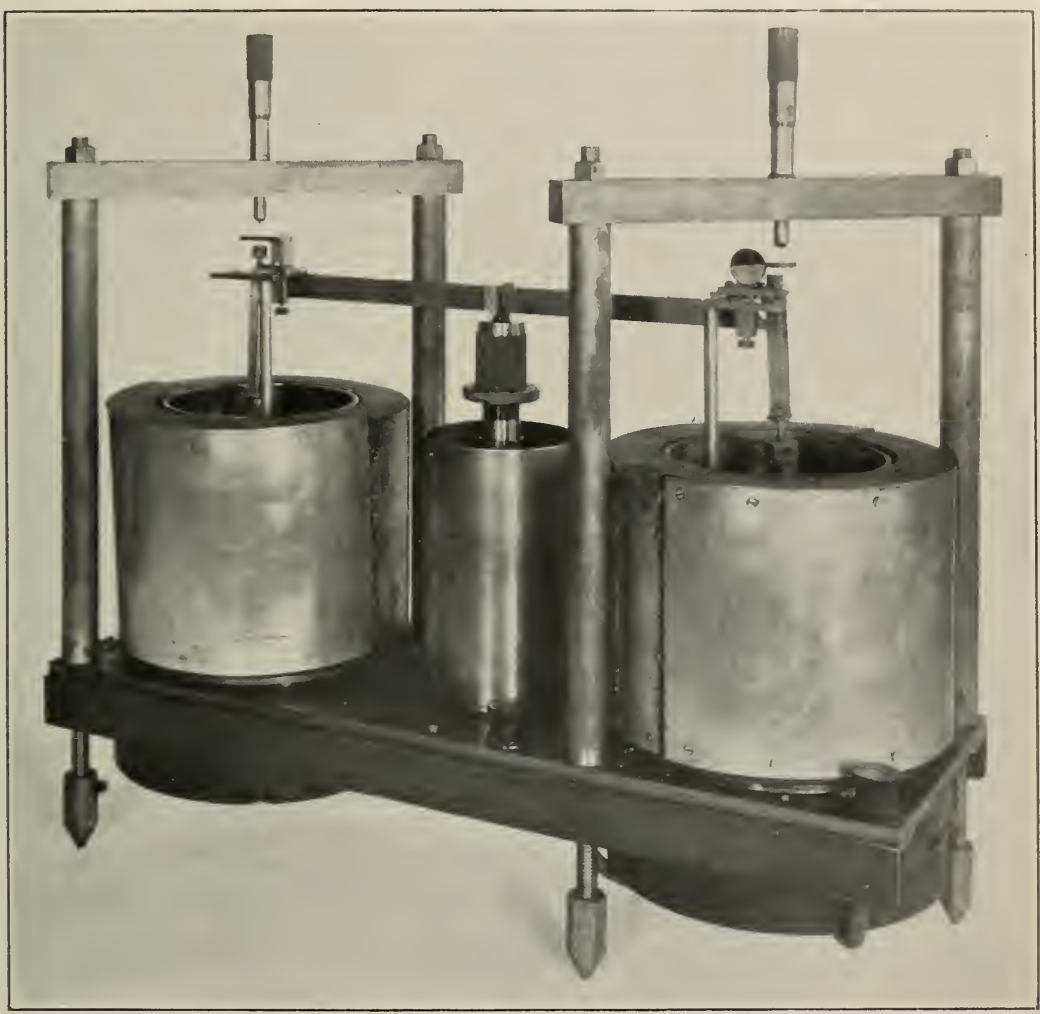

FIGURE 3.-Apparatus for the determination of the temperature coefficient of the rigidity modulus 
ie springs. The upper end of spring $s_{1}$ is cornected to the lever $L$ y means of the steel link $R_{1}$ and spring $s_{2}$ by the invar link $R_{2}$. hese links are attached to the clamps by universal joints. The djustable pivots $P_{1}$ and $P_{2}$ at the upper ends of the links rest in small oles near the extremities of the lever arm $L$. The arm $L$ rests on a entrally attached knife-edge in a $\mathrm{V}$ groove of the screw cap $Q$ of he central rod $E$. The function of the screw cap is to raise or to swer the lever arm $L$. Central rod $E$ is permanently attached to the teel base plate $B$. The latter is 0.25 inch thick and is reinforced on ach side by the angle irons $A$. This additional rigidity was essential.

Two micrometers (not shown in the figure) were used to measure he vertical displacement ( $X$ in equation $(7)$ ) of the lever arm $L$ at he end platforms $K_{1}$ and $K_{2}$, located almost vertically above the prings. The rotating mirrors $M_{1}$ and $M_{2}$ were parts of an optical sver and were used for measuring the change in the end deflections $f$ the lever arm as the temperature of the test spring $s_{2}$ was varied. the upper rod $F_{1}$ of the support for mirror $M_{1}$ was made of steel and od $F_{2}$ of invar. The lower rods of the support were of steel and were ttached to the heavy rings of the bath vessels $U_{1}$ and $U_{2}$.

The electrical heaters $H$ are placed, as shown in Figure 2, in the ower cups $N_{1}$ and $N_{2}$ of the bath vessels. In order to reduce the ransfer of heat to or from the base plate $B$ to a minimum, each cup is ttached to the base only at four points by means of the screw and rasher assembly $S W$. The bath is insulated at the bottom by the akelite cover $B a$, and at the sides by felt and, the circular boxes $I$ are lled with powdered cork $D$. Alcohol was used as the bath liquid. Co obtain low temperatures solid carbon dioxide was dropped into he alcohol.

\section{(b) APPARATUS FOR TESTING SMALL SPRINGS}

Samples of three materials-tungsten, elinvar, and modulvarvere of much smaller diameter than that of the others. Springs of he size otherwise required would not support the frame of the apparaus for measuring the temperature coefficient of Young's modulus of lasticity (to be described later) and the stiffness was believed to be oo small in comparison with the friction of the knife-edge in the pparatus for the rigidity modulus and would thereby introduce coniderable error into the measurements. For this reason another pparatus was constructed which had the added advantage that it ould be used to measure both temperature coefficients.

The general arrangement of the parts is shown in Figure 4. Quartz ods $Q$ were used for the vertical supports. The springs $s_{1}$ and $s_{2}$ were igidly clamped together by means of a small quartz rod $Q_{1}$ and were ;iven the required extension or twist by raising or turning the rod $R$. [wo springs were necessary in order to hold the test spring vertical ind to reduce the lateral vibrations which it seemed impossible to liminate. The lower or test spring was immersed in a bath of alco1ol, the temperature of which was controlled by an electric heater and olid carbon dioxide. The temperature of the upper or auxiliary pring, which was uncontrolled, was determined by means of copperconstantan thermocouples mounted at points $C_{1}$ and $C_{2}$. The temperavure at point $C_{3}$ was also determined in order to be able to correct the spring deflection for the change in length of the brass rod $R$. The shange in the extension of the springs, as the temperature of the test 
spring was varied, was measured by means of the optical system shown in Figure 4. The mirror $M$ was pivoted, a deflection of the spring causing the mirror to rotate. The connecting wire $T$ was of tungsten which was used because of its small temperature coefficient of expansion. A small counterweight $W$ kept the wire under a

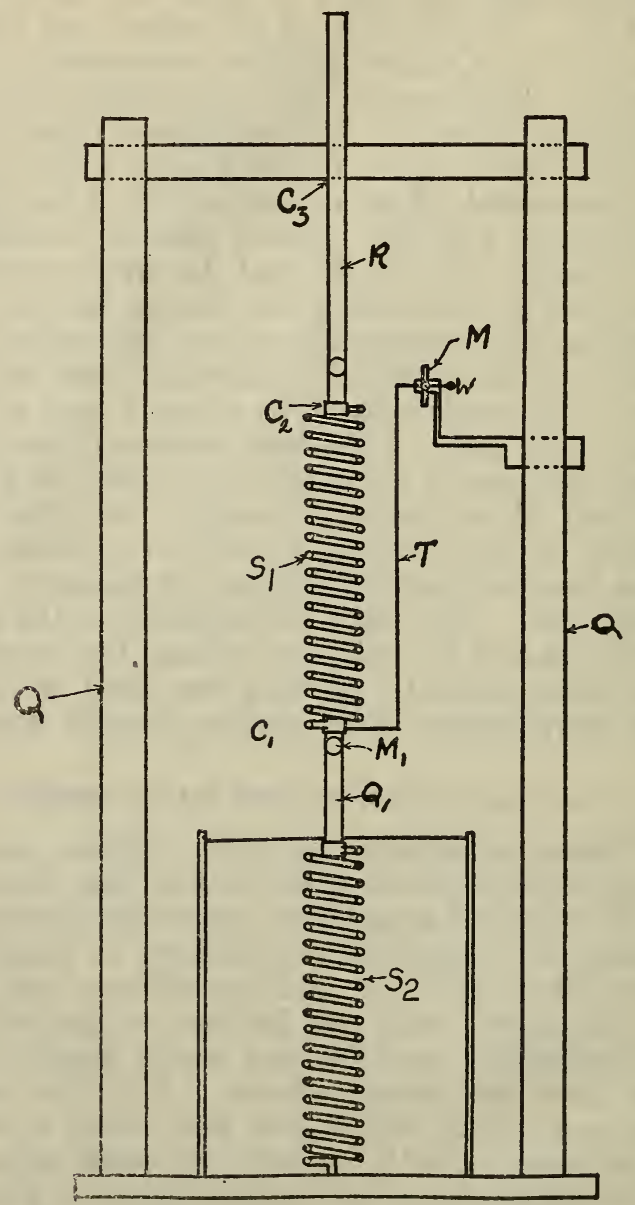

FIGURE 4.-Simplified diagram of the apparatus used for the determination of the temperature coefficient of the elastic moduli of materials of which only fine wire was available

constant tension. The method of computing the temperature co. efficients is essentially the same as that for springs of larger wires.

In determining the temperature coefficient of Young's modulus mirrors $M_{1}$ mounted on the quartz rod $Q_{1}$ were used to measure botl the initial angular deflection and the change in angular deflection as the temperature was varied. 


\section{MATERIALS}

(a) CHEMICAL COMPOSITION

The chemical composition of each of the materials is given in Table 1. The analyses were made by the chemistry division.

TABLE 1.-Chemical composition of the materials

(a) NONFERROUS

\begin{tabular}{|c|c|c|c|c|c|c|c|c|c|c|c|c|c|c|}
\hline \multirow{2}{*}{ 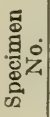 } & \multirow{2}{*}{ Material } & \multicolumn{13}{|c|}{ Elements (in per cent) } \\
\hline & & $\mathrm{Cu}$ & $\mathrm{Zn}$ & Al & $\mathrm{Pb}$ & $\mathrm{Sn}$ & $\mathrm{Ni}$ & $\mathrm{Si}$ & $\mathrm{Fe}$ & $\mathrm{P}$ & Mn & $\mathrm{Mg}$ & $\mathrm{C}$ & $\mathrm{Be}$ \\
\hline 3 & Phosphor bronze.- & 95.3 & n. d. & & n. d. & 4.3 & n. d. & & n. d. & 0.4 & & & & \\
\hline 14 & -...do do... & 94.6 & n. d. & & n. d. & 5.1 & 10.01 & & n. d. & .29 & n. d. & & & \\
\hline 15 & .....do do & 95.0 & n. d. & & n. d. & 4.6 & n. d. & & n. d. & .29 & n. d. & & & $-\ldots$ \\
\hline 10 & Monel metal & 33.2 & & & & & 63.8 & 0.03 & 1.7 & $-\ldots$ & 1.1 & -- & 0.10 & --- \\
\hline 16 & Nickel silver_.....- & 61.7 & 27.4 & & n. d. & .03 & 10.5 & & 1.05 & $\ldots$ & 1.03 & & & $\ldots$ \\
\hline 17 & .....do do & 62.2 & 23.5 & & n. d. & n. d. & 14.2 & & 1.05 & & 1.03 & & & \\
\hline 18 & ......do_ & 64.4 & 16.2 & & n. d. & n. d. & 19.3 & & 1.05 & $\ldots$ & 1.03 & - & & $\ldots$ \\
\hline 19 & ....._do _. & 64.8 & 25.4 & & n. d. & n. d. & 9.8 & L. & 1.05 & ---- & 1.03 & -- &. & $-\cdots$ \\
\hline & do & & 170 & & & n. d. & 10.3 & & 1.00 & & & & & \\
\hline 27 & Duralumin & $\begin{array}{r}64.5 \\
4.4\end{array}$ & 17.0 & 293.63 & $\begin{array}{l}\text { n. d. } \\
\text { n.d. }\end{array}$ & n. d. & 18.4 & .27 & $\begin{array}{r}1.05 \\
.58\end{array}$ & 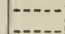 & $\begin{array}{r}1.03 \\
.61\end{array}$ & 0.51 & & -- \\
\hline 30 & Brass & 73.0 & 226.93 & & 10.02 & $\cdots+\cdots$ & n. d. & & 1.05 & & & & & \\
\hline 34 & Beryllium bronze & 98.1 & & & & & & & $-\ldots$ & & & & & 1.9 \\
\hline
\end{tabular}

(b) FERROUS

\begin{tabular}{|c|c|c|c|c|c|c|c|c|c|c|c|}
\hline \multirow{2}{*}{$\begin{array}{l}\text { Spec- } \\
\text { imen } \\
\text { No. }\end{array}$} & \multirow{2}{*}{ Material } & \multicolumn{10}{|c|}{ Elements (in per cent) } \\
\hline & & $\mathrm{C}$ & $\mathrm{Mn}$ & $\mathbf{P}$ & $\mathrm{S}$ & $\mathrm{Cr}$ & $\mathrm{Si}$ & $\mathrm{V}$ & $\mathrm{Ni}$ & W & $\mathrm{Fe}$ \\
\hline 1 & Chromium vanadium steel & 0.53 & 0.54 & 0.014 & 0.025 & 0.98 & 0.28 & 0.24 & & & \\
\hline 4 & Piano wire. & .94 & .34 & .023 & .018 & & & & & & \\
\hline 11 & do do & .86 & .34 & .025 & .019 & $-\ldots$ & .19 & & & & \\
\hline $\begin{array}{r}5 \\
12\end{array}$ & Oil-tempered wire & $\begin{array}{l}.66 \\
.67\end{array}$ & $\begin{array}{l}.80 \\
.78\end{array}$ & $\begin{array}{l}.009 \\
.016\end{array}$ & $\begin{array}{l}.040 \\
.034\end{array}$ & 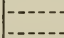 & .13 & - & & & \\
\hline 8 & Nickel steel & 13 & .48 & 018 & .019 & & & & & & \\
\hline 9 & do & .18 & .48 & .010 & .016 & & & & $\begin{array}{l}4.97 \\
3.50\end{array}$ & & \\
\hline 6 & High-carbon steel... & .83 & .64 & .030 & .024 & & & & & & \\
\hline 13 & do & .89 & .36 & .01 & .02 & ... & .16 & & 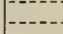 & & \\
\hline 22 & Stainless steel (KA2) _. & .14 & & & & 17.4 & & & 8. 63 & & \\
\hline 24 & Stainless steel (Enduro A) & $\begin{array}{l}.05 \\
.08\end{array}$ & & & & $\begin{array}{l}17.5 \\
17.6\end{array}$ & & & $\begin{array}{r}8.97 \\
.13\end{array}$ & & \\
\hline 25 & Stainless steel (Enduro AA) . & .06 & & & & 17.3 & & & .18 & & \\
\hline $\begin{array}{l}26 \\
29\end{array}$ & Stainless steel No. 1 & .08 & & & & 11.6 & & & .65 & & $-\cdots$ \\
\hline $\begin{array}{l}29 \\
31\end{array}$ & $\begin{array}{l}\text { Silico-manganese steel } \\
\text { Elinvar }\end{array}$ & $\begin{array}{l}.58 \\
.84\end{array}$ & $\begin{array}{l}1.13 \\
1.5\end{array}$ & & & 11.1 & $\begin{array}{r}1.88 \\
.14\end{array}$ & & 32.7 & 3. 9 & 249.8 \\
\hline 32 & Modulvar. & .16 & .18 & & -..- & .12 & .14 & & 34.9 & n. d. & 264.5 \\
\hline
\end{tabular}

1 Less than.

${ }^{2}$ By difference.

n. d.=not detected.

(b) FORM AND DIMENSIONS OF SPRINGS

The materials were obtained in the form of wires about $3 \mathrm{~mm}$ ( 0.125 inch) in diameter with the exception of those of elinvar, modulvar, and tungsten which were about $1.6 \mathrm{~mm}(0.06 \mathrm{inch})$ in diameter. The helical springs wound from the larger wires had the following approximate dimensions: Diameter of the coils, $3.7 \mathrm{~cm}$ (1.5 inches), length of unstressed spring $9 \mathrm{~cm}$ (3.6 inches) and number of coils, 11. The dimensions of those made from the smaller wires were: 
Diameter of the coils, $2 \mathrm{~cm}$ ( $0.8 \mathrm{inch})$; length of unstressed springs, $9 \mathrm{~cm}$ (3.6 inches); and number of coils, 16 .

\section{(c) HEAT TREATMENT AND HARDNESS}

The heat treatment and the Vicker's hardness number of the springs after winding are given in Table 2. The heat treatments were in most cases made by the metallurgical division.

TABLE 2.-Heat treatment and hardness number of springs

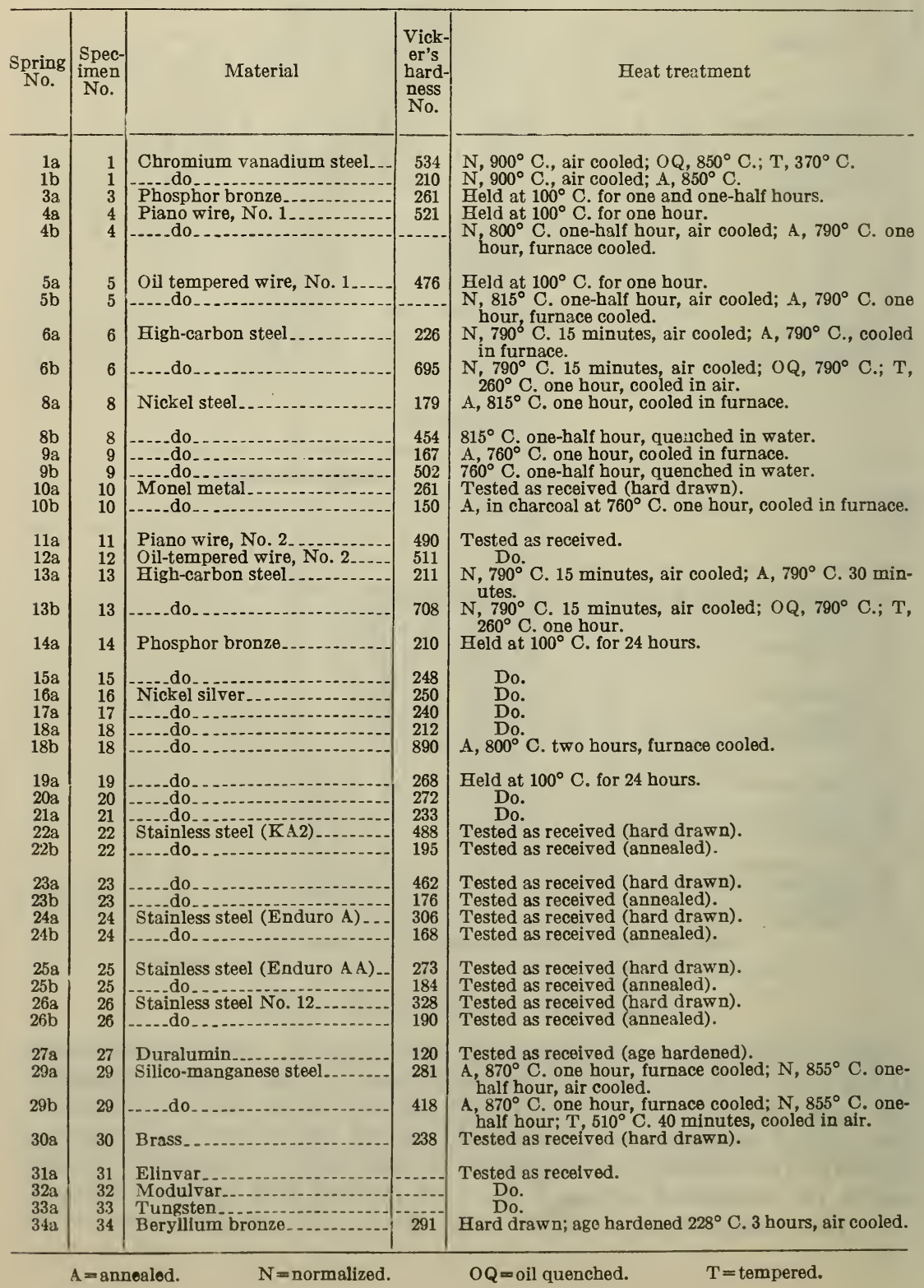


In the cases where the spring is listed as having been "tested as received," the springs were coiled at room temperature from the wire as received and were subjected to no heat treatment. No detailed information is available relative to the heat treatment or cold work of the wires other than that given in the table. A number of the springs were subjected to a temperature of $100^{\circ} \mathrm{C}$. to relieve trapped stresses produced in winding the spring. In every case the heat treatment refers to that given the coiled springs.

In general, it was planned to make tests on the springs when the material was in the most favorable condition as to heat treatment or cold work from the viewpoint of its use as an elastic element. In most cases data were also obtained on the spring in the annealed condition.

\section{EXPERIMENTAL PROCEDURE AND RESULTS}

(a) EXPERIMENTAL PROCEDURE

For the purpose of determining the extensions $X_{1}$ and $X_{2}$ of the installed springs an auxiliary knife-edge balance was used to support lever $L$ (fig. 2) at its center. The cap ordinarily supporting the lever $L$ was lowered and then the deflections of the platforms $K_{1}$ and $K_{2}$, for various weights on the auxiliary balance, were measured by means of micrometers. These readings were plotted against the loads on the auxiliary balance and the resulting curve for each spring was extrapolated in order to determine the reading at zero load. The latter reading was determined in this manner before and after each experiment while the springs were at room temperature.

Before subjecting the springs to the temperature cycle, the auxiliary balance was disengaged and the springs were extended a desired amount by raising the screw cap on the center rod $L$. The readings of the micrometers in contact with $K_{1}$ and $K_{2}$ for this position of the lever arm and those for the zero position as above determined sufficed to give the initial extensions $X_{1}$ and $X_{2}$ of the auxiliary and test springs, respectively.

To guard against errors arising from elastic after working, the drift, or the change with time of the deflection of the springs at room temperature, was observed with the optical lever system. In most cases the springs tested showed very small or no relative drift, but when the relative drift was initially large, sufficient time was allowed for the rate to decrease to a small value.

The change in the deflections of the two springs during the temperature cycle was obtained by means of the two optical levers. In this cycle the auxiliary spring was maintained at $+30^{\circ} \mathrm{C}$. while the temperature of the test spring was changed from $+50^{\circ}$ to $-50^{\circ} \mathrm{C}$. and back to $+50^{\circ} \mathrm{C}$. The temperature during a measurement was held constant within $0.5^{\circ} \mathrm{C}$. The temperature of the auxiliary spring was determined by means of a mercurial thermometer, the bulb of which was in the bath near the midportion of the spring. The temperature of the test spring was determined by means of two calibrated liquid-inglass thermometers with the bulbs placed in the bath at points near the upper and lower ends of the spring. The average of the readings obtained before and after every observation on the change of deflection of the springs was taken as the temperature of the test spring. The temperature of one test spring was also determined during a temperature cycle by means of two thermocouples which were soldered to the 
spring, one at the top and the other at the bottom. The results by the two methods agreed within $0.5^{\circ} \mathrm{C}$. throughout the range from $+50^{\circ}$ to $-50^{\circ} \mathrm{C}$.

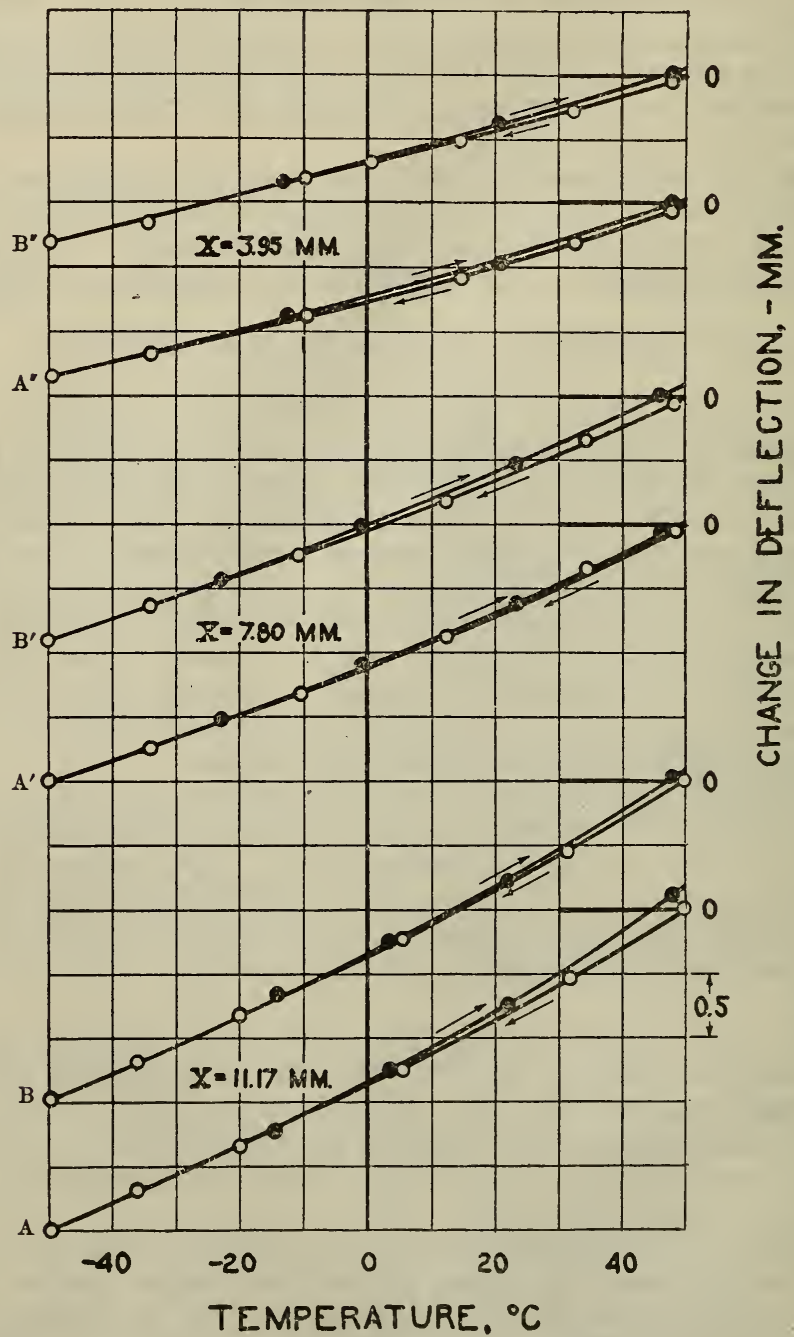

Figdre 5.-Change in deflection of spring No. 23a with change in temperature

The optical lever above the test spring gave the data shown in curves $B, B^{\prime}$, and $B^{\prime \prime}$ and the optical lever above the auxiliary spring that in curves $A, A^{\prime}$, and $A^{\prime \prime}$ with the sign of the ordinate reversed.

(b) CORRECTIONS APPLIED TO THE READINGS

During the temperature cycle to which the test spring was subjected, which was almost invariable from $+50^{\circ}$ to $-50^{\circ} \mathrm{C}$. and then hack to $+50^{\circ} \mathrm{C}$., the temperature of other parts of the apparatus also changed with consequent changes in dimensions which in some cases contributed to the observed deflections. The source and amount 
of these extraneous deflections were determined with considerable care and their effect eliminated from the results. These parts were $(a)$ the central invar rod and the caps ( $E$ and $Q$, fig. 2), and (b) the system of rods which support the mirror $M_{2}$.

\section{(c) METHOD OF REDUCING THE DATA}

The method of reducing the data was essentially the same in all cases and is most conveniently presented by giving the details of the reduction for a typical case. The data obtained experimentally on spring No. 23a (stainless steel $K A 2$ ) are shown graphically in Figure 5. The ordinates represent the change $x$ in the initial deflection and the abscissas the corresponding temperatures of the test spring. The deflections for temperatures decreasing are represented by open circles and those for temperatures increasing, by filled circles. The deflections obtained by means of the optical mirror above the auxiliary spring for mean initial deflections of the springs of $11.17,7.80$, and 3.95 $\mathrm{mm}$ are given, with signs reversed, in the curves marked $A, A^{\prime}, A^{\prime \prime}$, respectively, and those obtained above the test spring, corrected for the thermal expansion of the supports of the optical lever, are given by curves $B, B^{\prime}$, and $B^{\prime \prime}$.

For most materials the points for increasing and decreasing temperature fell on the same curve within very close limits, but for spring No. $23 a$ (fig. 5) two distinct curves were obtained. In all cases like the latter, the points midway between the two curves were used to evaluate the slope $\frac{d x}{d \theta}$ (equation $\left.(7)\right)$. The medians of the curves in Figure 5 may be regarded, within the errors of observations, as arcs of circles. Hence if we draw two straight lines, one joining the two points of the arc corresponding to $+50^{\circ}$ and $0^{\circ}$ C., and the other joining the points corresponding to $0^{\circ}$ and $-50^{\circ} \mathrm{C}$., the slopes of these two lines will give the value of $\frac{d x}{d \theta}$ at the temperatures $+25^{\circ}$ and $-25^{\circ} \mathrm{C}$. On this basis the following values were derived from Figure 5 .

Rate of change of deflection $\frac{d x}{d \theta}$

$\theta=25^{\circ} \mathrm{C}$.

\begin{tabular}{|c|c|c|c|}
\hline $\mathrm{X}$ & Curves A & Curves B & Average \\
\hline $\begin{array}{r}m m \\
3.95 \\
7.80 \\
11.17\end{array}$ & $\begin{array}{r}m m /{ }^{\circ} C . \\
0.00157 \\
.00226 \\
.00293\end{array}$ & $\begin{array}{r}m m /{ }^{\circ} C . \\
0.00143 \\
.00217 \\
.00282\end{array}$ & $\begin{array}{r}m m /{ }^{\circ} C \\
0.00150 \\
.00221 \\
.00288\end{array}$ \\
\hline \multicolumn{4}{|c|}{$\theta=-25^{\circ} \mathrm{C}}$. \\
\hline $\begin{array}{r}3.95 \\
7.80 \\
11.17\end{array}$ & $\begin{array}{r}0.00118 \\
.00180 \\
.00227\end{array}$ & $\begin{array}{r}0.00130 \\
.00177 \\
.00228\end{array}$ & $\begin{array}{r}0.00124 \\
.00178 \\
.00228\end{array}$ \\
\hline
\end{tabular}

These average values of $\frac{d x}{d \theta}$ at $+25^{\circ}$ and $-25^{\circ} \mathrm{C}$. are plotted in Figure 6 against $X$, the mean initial deflection of the springs. The points fall on straight lines within the error of the experiments. Each line in the figure is made to pass through a point, the coordinates of 
which are the mean values of $X$ and of $\frac{d x}{d \theta}$, and is drawn so that it appears to the eye to have the least deviation from the experimental points. The intersection of these lines with the axis of the ordinates

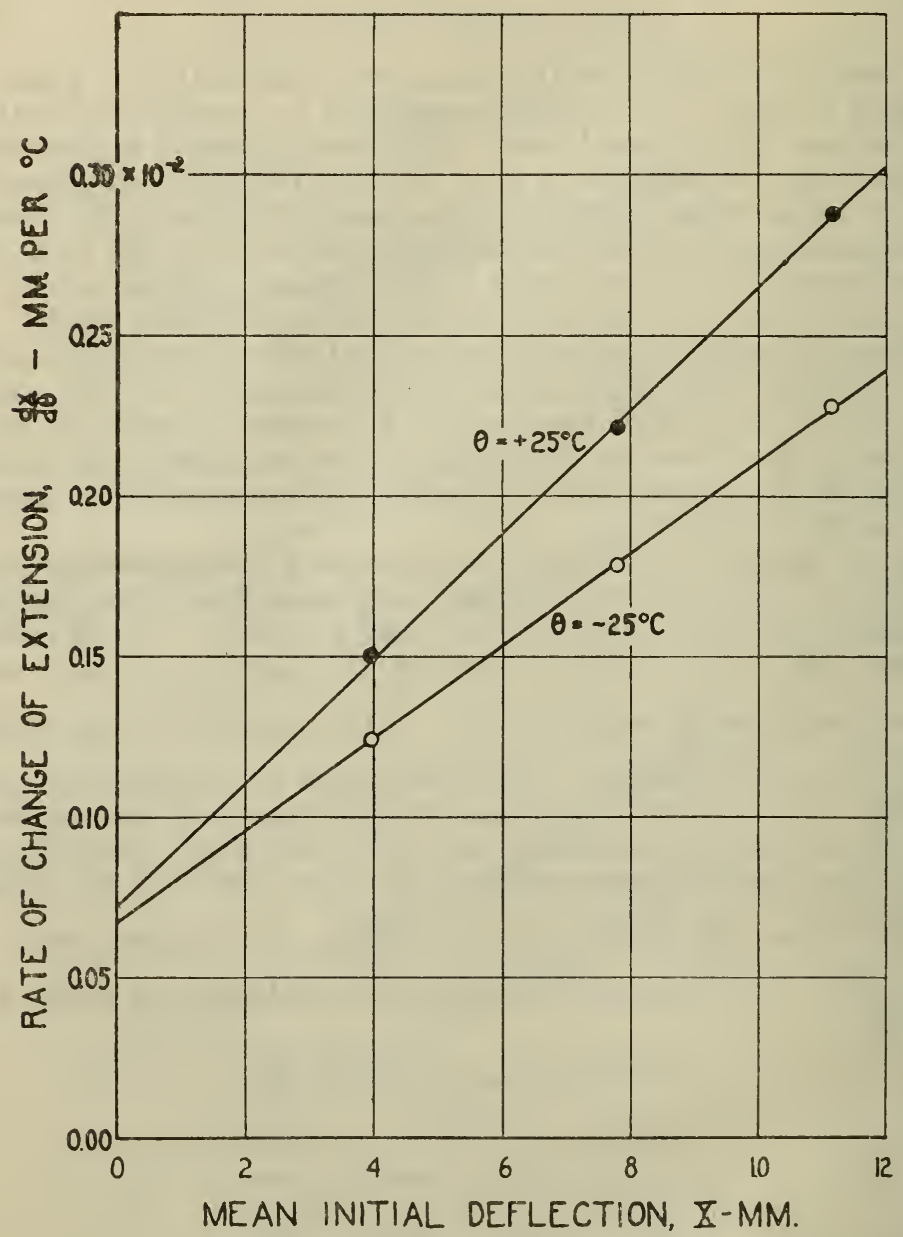

FIGURE 6.-Relation of the rate of change in the extension, $\frac{d x}{d \theta}$, of the spring No. 23a with temperature to the mean initial exlension $X$ of the springs

gives the values of $\frac{d x_{0}}{d \theta}$, one of the quantities in the working formula, equation (7). The following quantities were obtained from Figure 6 .

\begin{tabular}{|c|c|c|c|}
\hline $\begin{array}{c}\text { Tem- } \\
\text { pera- } \\
\text { ture }\end{array}$ & $\begin{array}{c}X=10 \mathrm{~mm} \\
\frac{d x}{d \theta}\end{array}$ & $\begin{array}{c}X=0 \\
\frac{d x_{0}}{d \theta}\end{array}$ & $\begin{array}{c}\frac{2}{\bar{X}}\left(\frac{d x}{d \theta}-\frac{d x_{0}}{d \theta}\right) \\
\times 10^{5} \text { per }{ }^{\circ} \mathrm{C} .\end{array}$ \\
\hline${ }^{\circ} \mathrm{C}$. & $m m /{ }^{\circ} \mathrm{C}$. & $m m /{ }^{\circ} \mathrm{C}$. & \\
+25 & 0.00265 & 0.00073 & 38.4 \\
-25 & .00211 & .00068 & 28.6 \\
\hline
\end{tabular}


The thermal coefficient of expansion $\alpha$ of this alloy is stated to be $1.6 \times 10^{-5}$. Hence, using the working formula (7), the temperature coefficient $m$ is found to be

$$
\begin{aligned}
m_{25} & =-40.0 \times 10^{-5} \text { per }{ }^{\circ} \mathrm{C} . \\
m_{-25} & =-30.2 \times 10^{-5} \text { per }{ }^{\circ} \mathrm{C} .
\end{aligned}
$$

The average of the above values is $-35.1 \times 10^{-5}$ which is $m_{0}$, the coefficient at $0^{\circ} \mathrm{C}$. The ratio of two coefficients $m_{25} / m_{-2}$ is 1.32 .

\section{(d) EXTENSION AT ZERO TENSION}

It was seen in Figure 6 that the straight lines through the observed points cut the axis of the ordinates at two points the mean ordinate of which is $+70 \times 10^{-5} \mathrm{~mm}$ per ${ }^{\circ} \mathrm{C}$. This is the rate of deflection for the case of initial zero tension.

If the change in deflection with temperature at initial zero tension is due only to the expansion of the parts, it can be shown that

$$
x_{0}=\frac{c+l}{1+S_{1} / S_{2}}
$$

where $c$ is the sum of the expansions of the parts exterior to the test spring ( $a_{2}$ and $b_{2}$, fig. 1$)$ and $l$ that of the test spring. It follows that

$$
\frac{d x_{0}}{d \theta}=\frac{\frac{d c}{d \theta}+\frac{d l}{d \theta}}{1+S_{1} / S_{2}}
$$

The contraction $c$ of the spring assembly extending from the base plate to the lever arm $L$ (fig. 2), but exclusive of that of the test spring, was determined when the temperature of the bath was changed from $+50^{\circ}$ to $-50^{\circ} \mathrm{C}$. To determine this the test spring was replaced by a rod of phosphor bronze for which the thermal coefficient of expansion was known. While the temperature of the auxiliary spring was maintained constant, the change in its deflection was observed at a number of temperatures of the phosphor oronze rod in the range from $+50^{\circ}$ to $-50^{\circ} \mathrm{C}$. From these deflections, together with the known contraction of the phosphor bronze rod and the previously determined contraction of the central rod, the contraction $c$ was evaluated and found to be linear with temperature. Four determinations gave a mean value for $\frac{d c}{d \theta}$ of $(56 \pm 2) 10^{-5} \mathrm{~mm}$ per ${ }^{\circ} \mathrm{C}$. Tests showed that $\frac{d c}{d \theta}$ did not differ sufficiently from the above value in the two branches of the temperature cycle to justify the use of separate values.

The value of $\frac{d x_{0}}{d \theta}$, computed from equation 9 is $+94 \times 10^{-5} \mathrm{~mm}$ per ${ }^{\circ} \mathrm{C}$. for the stainless steel spring for which data are given in Figures 5 and 6. The quantity $\frac{d c}{d \theta}$ was computed on the basis of a thermal coefficient of expansion of $1.6 \times 10^{-5}$ per ${ }^{\circ} \mathrm{C}$.. and a length of spring $156547-33-2$ 
of $8.1 \mathrm{~cm}$. The quantity $\frac{d c}{d \theta}$ has the value given above and $S_{1} / S_{2}$ is 0.96. There is a difference of $24 \times 10^{-5} \mathrm{~mm}$ per ${ }^{\circ} \mathrm{C}$. between the above computed value of $\frac{d x_{0}}{d \theta}$ and the average of the two values obtained from Figure 6. Since experimental errors and the possibility that too high a value of the temperature coefficient of expansion was used account only for a small part of the difference, this particular test spring had a contraction during the temperature cycle other than that which can be evaluated on the basis of pure thermal expansion.

A similar comparison of the two determinations of $\frac{d x_{0}}{d \theta}$ was made for all of the other springs. For springs shaped from hard-drawn material the above discussed difference proved to be as large as $28 \times 10^{-5}$ $\mathrm{mm}$ per ${ }^{\circ} \mathrm{C}$. On the other hand, for springs which were annealed or heat treated after being shaped from the material in the "as-received" condition, the difference was smaller than $6 \times 10^{-5} \mathrm{~mm}$ per ${ }^{\circ} \mathrm{C}$.

\section{(e) EXPERIMENTAL RESULTS}

The values obtained for the temperature coefficient $m_{0}$ of the modulus of rigidity at $0^{\circ} \mathrm{C}$. of the various springs tested are given in Table 3. In addition, the heat treatment, the maximum shear stress, the ratio $\frac{m_{25}}{m_{-25}}$ and the value of the thermal coefficient of expansion $\alpha$ used in evaluating $m$ are given for each spring.

The temperature coefficient $m_{0}$ is for all practical purposes the average coefficient for the temperature range $-50^{\circ}$ to $+50^{\circ} \mathrm{C}$. A measure of the variation of the coefficient with temperature is given by the ratio $\frac{m_{25}}{m_{-25}}$.

The values of the maximum shear stress given in Table 3 were computed from the formula

$$
f=\frac{2 L r}{a^{3}}
$$

in which $f$ is the maximum stress to which the specimen was subjected at its maximum extension, $L$ is the force producing the maximum extension, and $r$ and $a$ are the radii of the coils and wire, respectively. These stresses are all within the proportional limit.

\section{(f) ACCURACY OF RESULTS}

The sources of experimental error are as follows:

1. Uncertainty in the amount of the initial deflection of the springs, and therefore in the quantity $X$. A comparison of the values of the deflections obtained before and after the temperature cycle shows that the difference was in no case more than 2 per cent, and in most cases 


\section{TABLE 3.-Temperature coefficients of the elastic moduli}

(The temperature coefficients of the modulus of rigidity and modulus of elasticity are, respectively, $m$ and $e$, the subscripts of which denote the temperatures in degrees centigrade at which the values were determined. The coefficients $m_{0}$ and $c_{0}$ are also the average values in the temperature range $-50^{\circ}$ to $+50^{\circ}$ C.)

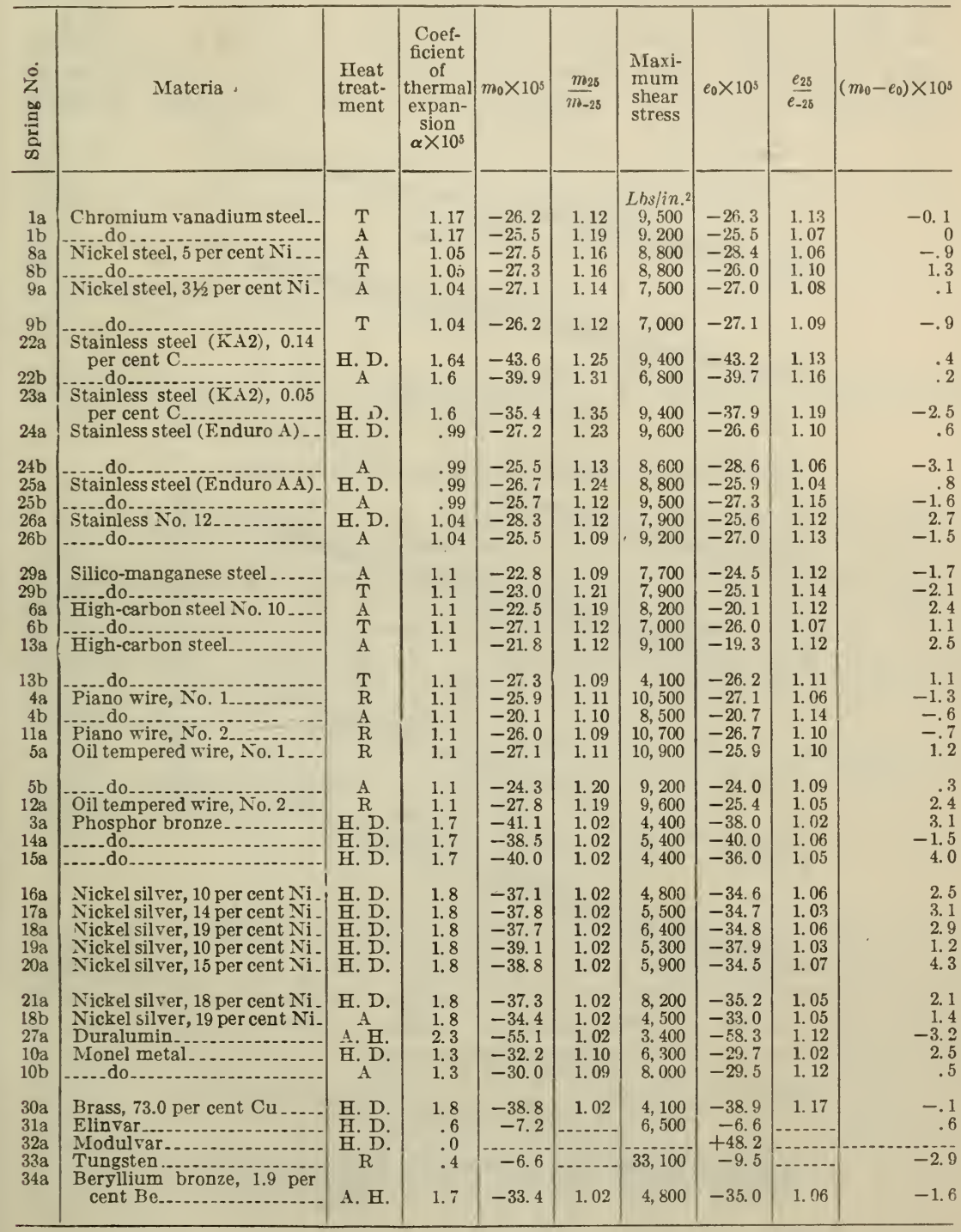

$\mathrm{T}=$ Tempered.

$\mathrm{A}=$ Annealed.

H. D. = Hard drawn.

$R=A$ s received.

A. H. = Age hardened, 
less than 1 per cent. Errors of the same amount are thus introduced in to the value of the temperature coefficient $m_{0}$.

2. Uncertainty in the measured values of the temperature of the springs. Tests showed the temperatures to be correct within $0.5^{\circ} \mathrm{C}$. (See Sec. II, 4, on Experimental Procedure and Results, p. 299.)

3 . The possibility that the contraction of a given test spring and its supports during a temperature cycle depends upon the defiection of the spring as well as the temperature. If this contraction depends

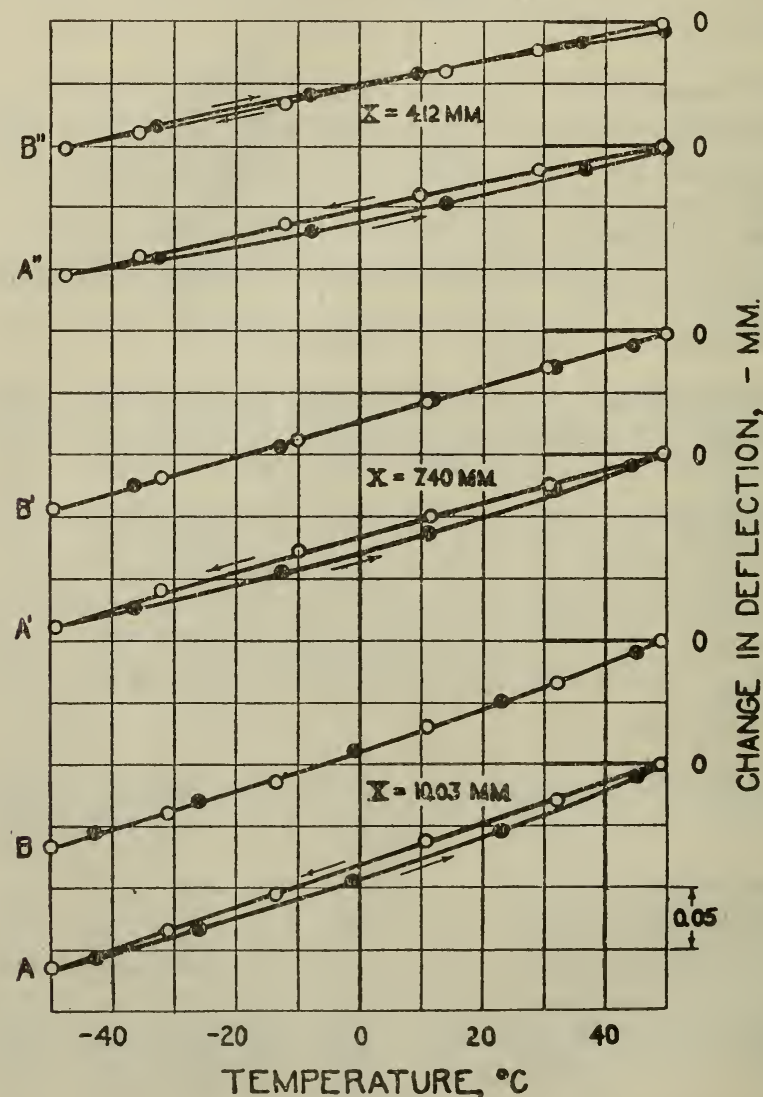

Figure 7.-Change in deflection of spring No. $6 a$ with change in temperature

The optical lever above the test spring gave the data shown in curves $B$, $B^{\prime}$, and $B^{\prime \prime}$, and the optical lever above the auxiliary spring that in the curves $A, A^{\prime}$, and $A^{\prime \prime}$ with the sign of the ordinate reversed.

upon the deflection of the spring the error from its neglect in determining the temperature coefficient will not be in excess of 2 per cent.

4. Possible error in the value of the coefficient of expansion of the sample materials. $\Lambda$ s this coefficient enters only as a second order correction term (equation (7)) large percentage errors in the value used will introduce only negligible errors in the final results.

Thus, any one determination of the temperature coefficient of rigidity ${ }_{\mathrm{b}} m_{0}$ may be in error by an amount as large as 4 per cent. 
In the determination of the ratio $\frac{m_{25}}{m_{-25}}$ the principal source of error was that in some cases the changes in deflection $x$, were observed to be different for decreasing and increasing temperatures. For example in Figure 7, showing the data obtained on spring No. 6a, the points for decreasing temperature as measured with the mirror above the auxiliary spring fall practically on a straight line, whereas the points for increasing temperature fall on a curve. In this and similar cases the mid line was used to represent the data. Although it is clear that $m_{0}$ obtained from the mid line is not open to an error larger than above stated, the same can not be said for the determinations of the ratio $\frac{m_{25}}{m_{-25}}$. The error in cases where the ratio is approximately unity will not exceed the 4 per cent above mentioned, otherwise it is likely to be larger, but is estimated not to exceed 10 per cent.

\section{TEMPERATURE COEFFICIENT OF YOUNG'S MODULUS OF ELASTICITY}

\section{DERIVATION OF THE WORKING FORMULA}

The apparatus used in the measurement of the temperature coefficient of Young's modulus of elasticity is shown in Figure 8. Only a description sufficient to explain the derivation of the working formula will be given here. The lower ends of the two springs $s_{1}$ and $s_{2}$, called, respectively, the auxiliary and the test springs, are attached to the separate bases, $B_{1}$ (not shown in the figure) and $B_{2}$, which are held fixed by suitable supports. Both of these springs are immersed in liquid temperature control baths.

By a process analogous to that followed in the derivation of the working formula for the temperature coefficient of the modulus of rigidity, we find

$$
\frac{1}{S_{2}^{\prime}} \frac{d S_{2}{ }^{\prime}}{d \theta}=-\frac{2}{\Phi}\left(\frac{d \phi}{d \theta}-\frac{d \phi_{0}}{d \theta}\right)
$$

where $\Phi$ is the mean of the absolute values of the initial twists of the two springs, $\phi$ and $\phi_{0}$ are, respectively, the changes with temperature $\theta$ in the angular deflection of the test spring for an initial twist $\Phi_{2}$ and for zero initial twist, and $S_{2}{ }^{\prime}$ is the stiffness of the spring with regard to angular deflection. The quantities $\phi$ and $\phi_{0}$ are measured from the position when the test spring is at $+50^{\circ} \mathrm{C}$. and the temperature of the auxiliary spring held constant, and taken as positive when the curvature of the coils of the test spring increases. The quantity $\Phi$ is positive when the initial twist of the test spring is such as to increase the curvature of its coils.

In terms of the constants of a helical spring the angular stiffness $S^{\prime}$ is

$$
S^{\prime}=\frac{\pi r^{4} E}{4 L}
$$

where $E$ is the Young's modulus of elasticity, $r$ is the radius of the wire, and $L$ is the length of the wire. This can also be represented for a given spring by

$$
S^{\prime}=\beta L^{3} E
$$




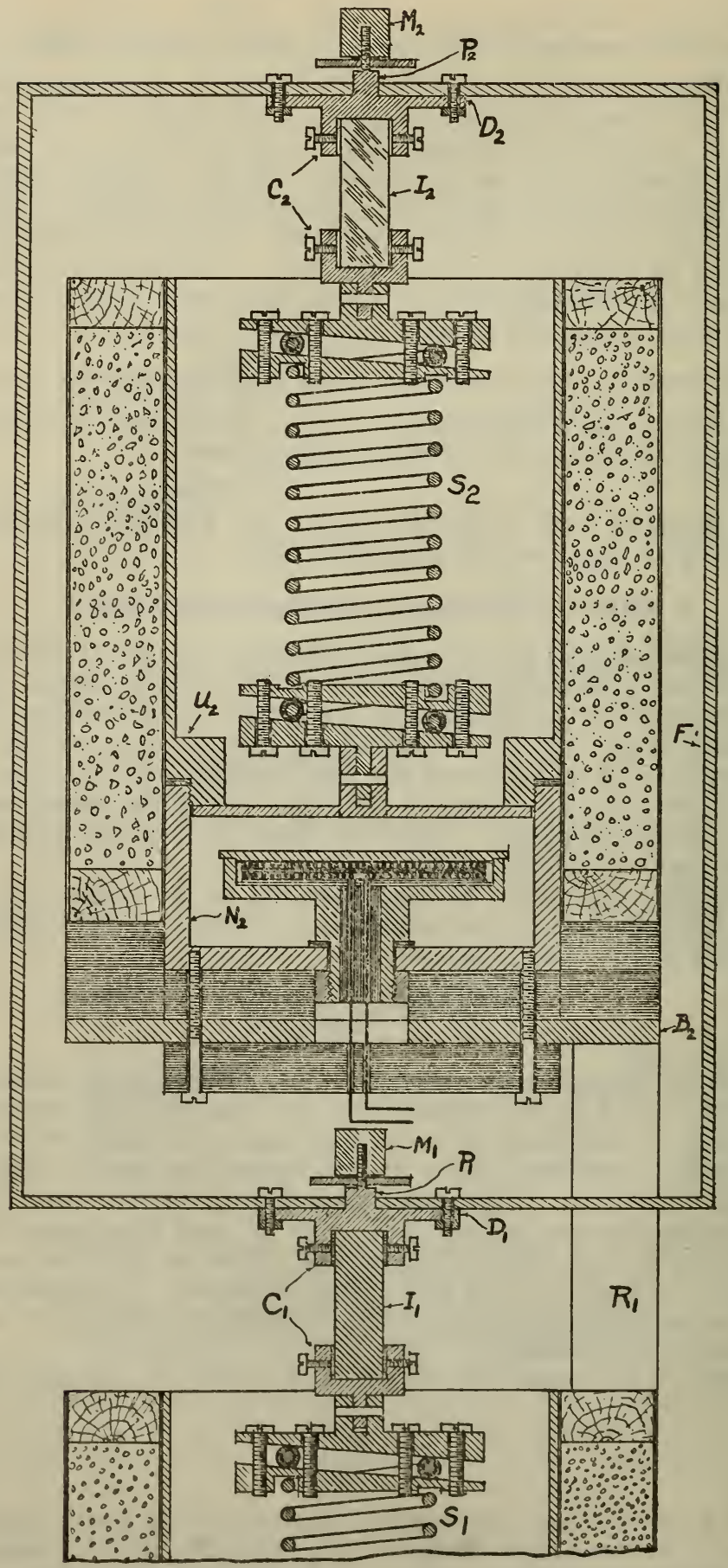

FIGURE 8.-Cross-sectional diagram of the apparatus for the determination of the temperature coefficient of Young's modulus of elasticity

(See the text for, the meaning of the letters.) 
where $\beta$ is a numerical constant and $L$ has the dimensions of length. $\beta$ is unaffected by the temperature if the ratio of $r$ to $L$ is invariant with temperature. Differentiating equation (11) with respect to $\theta$, and then dividing by equation (11) we obtain

$$
\frac{1}{S^{\prime}} \frac{d S^{\prime}}{d \theta}=\frac{1}{E}, \frac{d E}{d \theta}+3 \alpha
$$

where $\alpha$ is the temperature coefficient of linear expansion. After making the obvious substitution in equation (10) there results

$$
\frac{1}{E} \frac{d E}{d \theta}=-\frac{2}{\Phi}\left(\frac{d \phi}{d \theta}-\frac{d \phi_{0}}{d \theta}\right)-3 \alpha
$$

Let

$$
e=\frac{1}{E} \frac{d E}{d \theta}
$$

Equation (13) is the working formula for the experiments. The quantity $e$ is defined as the temperature coefficient of Young's modulus of elasticity. The quantities $\frac{d \phi}{d \theta}$ and $\frac{d \phi_{\mathrm{o}}}{d \theta}$ are the rates of change of the angular deflection of the test spring corresponding, respectively, to the mean of the absolute values and to the zero value of the initial deflections $\Phi_{1}$ and $\Phi_{2}$ of the springs.

\section{DESCRIPTION OF THE APPARATUS}

Figures 8 and 9 show a cross-sectional diagram and a photograph of the apparatus for measuring the temperature coefficient of Young's modulus. In Figure 8 the complete assembly is shown only for the upper spring. The construction of the lower spring assembly is the same as that of the upper. The base plates $\left(B_{2}\right.$, fig. 8$)$, which hold firmly the circular cups $\left(N_{2}\right)$, are bolted to two vertical rigid rods. Only one of the rods, $R_{1}$ is shown in the diagram, but both may be seen in Figure 9. The construction of the baths $U_{1}$ and $U_{2}$ and the lower connections of the springs $s_{1}$ and $s_{2}$ is similar to that in the apparatus for determining the temperature coefficient of the rigidity modulus of springs of heavy wire. Special clamps $C_{1}$ and $C_{2}$ terminating in circular disks $D_{1}$ and $D_{2}$ with central projections $P_{1}$ and $P_{2}$ are attached to the upper connections of the springs. The midportions of the clamps, $I_{1}$ and $I_{2}$ are square in cross section and one, $I_{2}$, is made of glass in order to obtain better temperature insulation. The springs after being given the initial deflection, are interconnected by frame $F$ which is sufficiently strong so as not to suffer appreciable distortion. Each of the disks $D_{1}$ and $D_{2}$ has 18 perforations circularly distributed near the edge, to facilitate the clamping to the frame $F$.

An optical system consisting of the mirrors $M_{1}$ and $M_{2}$, telescopes and scales, was used for measuring the angular deflection of each spring. There were two mirrors at both $M_{1}$ and $M_{2}$, inclined $90^{\circ}$ to each other. The scales were placed at such distances from each mirror so that a rotation of one degree of arc gave a change in reading of $2 \mathrm{~cm}$ on the scale. Readings on the scale were estimated easily to tenths of a millimeter. 


\section{MATERIALS}

The same springs were used to determine the temperature coefficients of both of the elastic moduli. These are described, together with the chemical composition and heat treatment, in the section on the temperature coefficient of the modulus of rigidity.

\section{EXPERIMENTAL PROCEDURE AND RESULTS}

(a) EXPERIMENTAL PROCEDURE

The test procedure was very similar to that followed in the experiments for determining the temperature coefficient of the rigidity modulus including the method of measuring and controlling the temperature of the springs. Similarly, the temperature of the auxiliary spring was maintained constant at $+30^{\circ} \mathrm{C}$. and that of the test spring varied in a cycle from $+50^{\circ}$ to $-50^{\circ} \mathrm{C}$. and back to $+50^{\circ} \mathrm{C}$. At various points in the cycle the change in deflection of both springs was measured by means of the optical system.

\section{(b) METHOD OF REDUCING THE DATA}

The method followed in reducing the experimental data will be presented by giving an example, using the data for high carbon steel spring No. 9b, given in Figure 10. Here the ordinates represent twice the change $\phi$ in the initial deflection $\Phi$ and the abscissas the temperature of the test spring. The open circles represent deflections observed at decreasing temperatures of the test spring and the filled circles, deflections at increasing temperatures. The mean initial deflections of the test spring, measured at room temperature, about $25^{\circ} \mathrm{C}$., were $92.0^{\circ}, 12.5^{\circ},-8.1^{\circ}$, and $-87.5^{\circ}$.

The lines through the observed points are not straight and may be regarded as arcs of circle. Hence, if the slopes of the two straight lines, one joining points on the arc at $0^{\circ}$ and $50^{\circ} \mathrm{C}$., and the other joining the points at $0^{\circ}$ and $-50^{\circ} \mathrm{C}$., are determined, we obtain, respectively, the quantity $\frac{2 d \phi}{d \theta}$ at the temperatures $25^{\circ}$ and $-25^{\circ} \mathrm{C}$. The results of such determinations for the curves in Figure 10 are:

\begin{tabular}{|c|c|c|}
\hline $\begin{array}{c}\text { Initial } \\
\text { deflection }\end{array}$ & $2 \frac{d \phi}{d \theta}$ & $2 \frac{d \phi}{d \theta}$ \\
\hline $\begin{array}{c}\text { Degrees } \\
92.0 \\
12.5 \\
-8.1 \\
-87.5\end{array}$ & $\begin{array}{r}\text { Degrees per }{ }^{\circ} \mathrm{C} . \\
\theta=25^{\circ} \mathrm{C} . \\
0.0242 \\
-.0036 \\
-.0025 \\
-.0225\end{array}$ & $\begin{array}{c}\text { Degrees per }{ }^{\circ} \mathrm{C} . \\
\theta=-25^{\circ} \mathrm{C} . \\
0.0215 \\
.0024 \\
-.0020 \\
-.0200\end{array}$ \\
\hline
\end{tabular}

These values of $2 \frac{d \phi}{d \theta}$ for $25^{\circ}$ and $-25^{\circ} \mathrm{C}$. are plotted against $\Phi$ in in Figure 11. The points for each temperature lie on a straight line within experimental errors. Each line is made to pass through a point whose coordinates are the means of coordinates of the plotted points and is so drawn that its deviation from these points appears by eye to be a minimum. The intersection of these lines with the axis 
B. S. Journal of Research, RP531

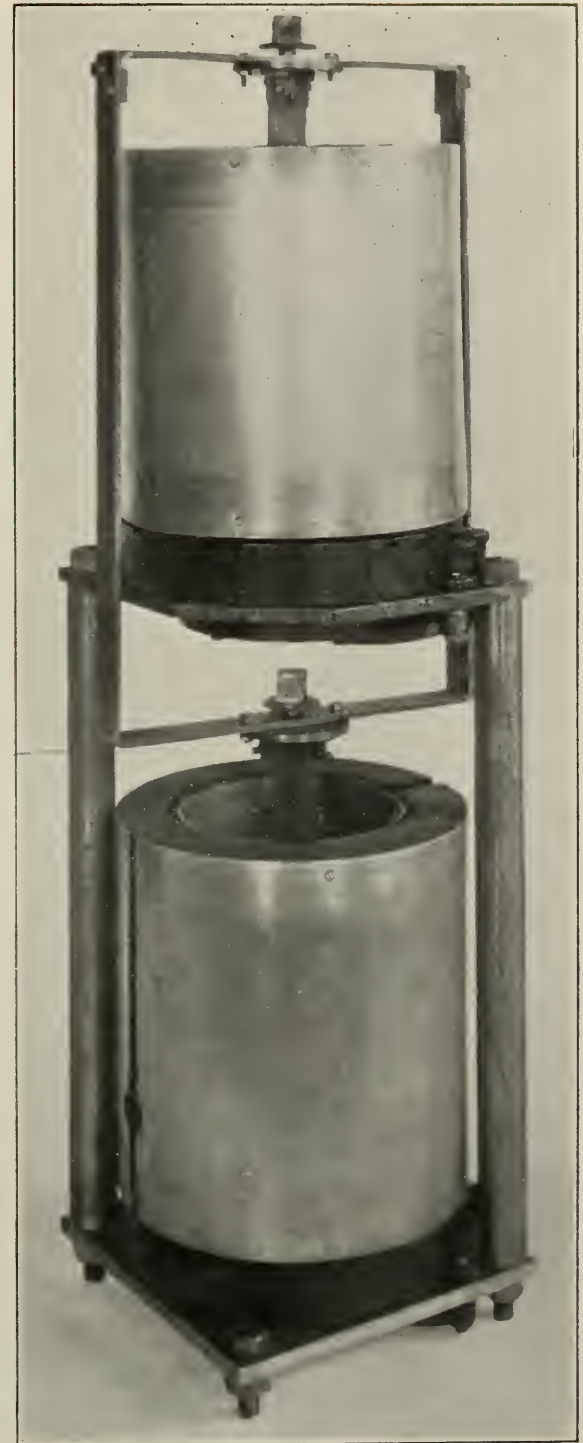

Figure 9.-Apparatus for the determination of the temperature coefficient of Young's modulus of elasticity 
of the ordinates gives the value of $2 \frac{d \phi}{d \theta}$. The following quantities are read from the graph:

\begin{tabular}{|c|c|c|c|c|}
\hline $\begin{array}{l}\text { Temper- } \\
\text { ature }\end{array}$ & $\Phi$ & $2 \frac{d \phi}{d \theta}$ & $\Phi$ & $2 \frac{d \dot{\phi}}{d \theta}$ \\
\hline $\begin{array}{l}\circ C . \\
+25 \\
-25\end{array}$ & $\begin{array}{c}\text { Degrees } \\
100 \\
100\end{array}$ & $\begin{array}{c}\text { Degrees per } \\
\text { ०. } \\
0.0260 \\
.0230\end{array}$ & $\begin{array}{c}\text { Degrees } \\
0 \\
0\end{array}$ & $\begin{array}{r}\text { Degrees per } \\
{ }^{\circ} \text {. } \\
\\
0 \\
0\end{array}$ \\
\hline
\end{tabular}

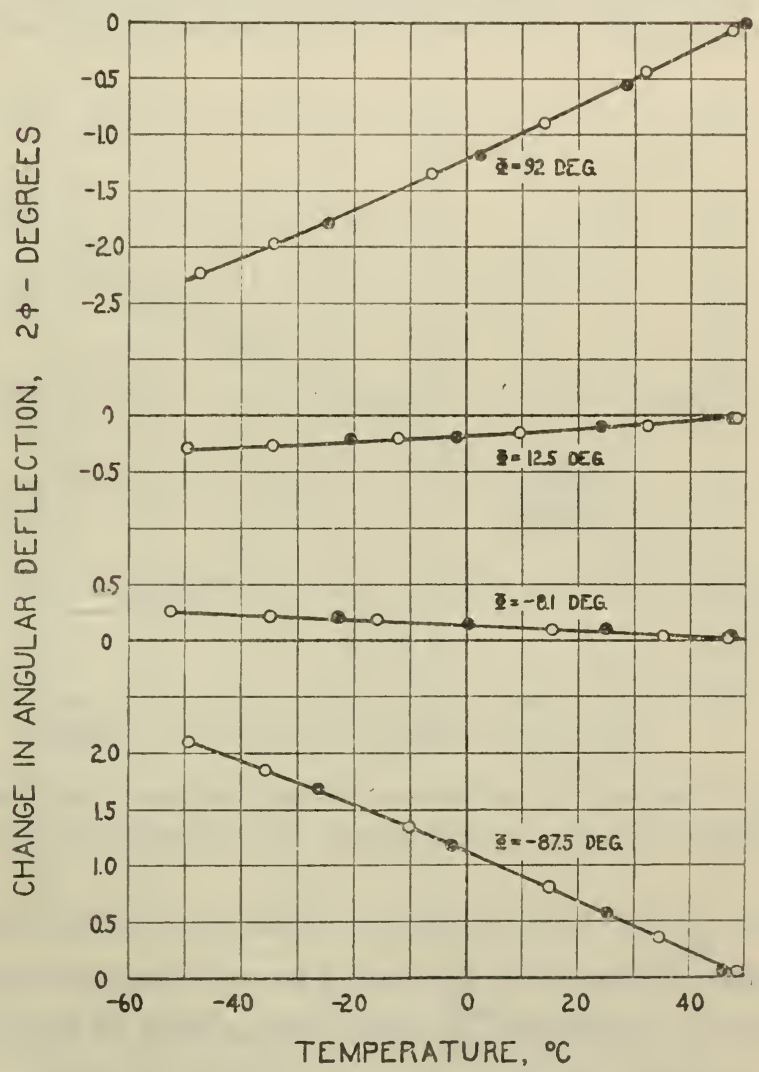

FIGURE 10.-Effect of change in temperature of test spring on the angular deformation $\Phi$ of spring No. $9 b$

The thermal coefficient of expansion $\alpha$ of this material is $1.1 \times 10^{-5}$. Inserting the above values into the working formula, equation (13) gives $-29.3 \times 10^{-5}$ at $+25^{\circ} \mathrm{C}$. and $-26.3 \times 10^{-5}$ at $-25^{\circ} \mathrm{C}$. for the temperature coefficient $e$ of Young's modulus of elasticity. The value at $0^{\circ} \mathrm{C}$. is the average of these values or $e_{0}=-27.8 \times 10^{-5}$ per ${ }^{\circ} \mathrm{C}$. The ratio of the values at $+25^{\circ}$ and $-25^{\circ} \mathrm{C}$. is

$$
\frac{e_{25}}{e_{-25}}=1.13
$$


The mean value $\Phi$ of the absolute values of the initial angular deflections of the two springs at $25^{\circ} \mathrm{C}$. is used in evaluating $e_{-25}$ and $e_{25}$ without the introduction of sensible error.

(c) EFFECT OF TEMPERATURE AT INITIAL ZERO ANGULAR DEFLECTION

The rate of change of angular deflection is plotted in Figure 12 against the mean initial angular deflection for springs of oil-tempered steel (No. 5a). The straight line $A$ represents the results of the tests on this spring when prepared from the original tempered material without subsequent heat treatments. It meets the axis of the ordinates at a point other than the origin, which means that this spring deflects with change in temperature when the initial angular deflection

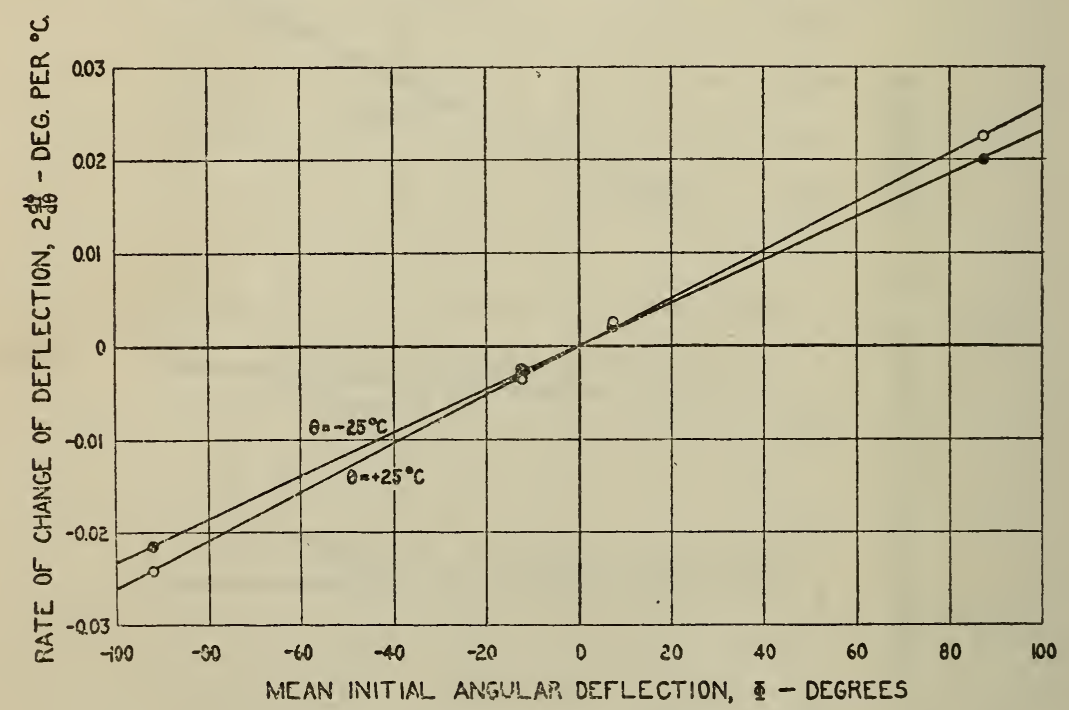

FIGURE 11.-Relation of twice the rate of change in angular deflection $\frac{2 d \phi}{d \theta}$ with temperature to the mean initial angular deflection $\Phi$ of spring $\mathrm{No} .9 \mathrm{~b}$

is zero. Let $\frac{d \psi_{0}}{d \theta}$ be the rate of change with temperature of the deflection of the test spring when the spring is unstressed and entirely free of the clamp $C$. Assuming $\frac{d \psi_{0}}{d \theta}$ to be independent of the deflection $\Phi$ it can be shown that $\frac{d \psi_{0}}{d \theta}=\left(1+S_{1}{ }^{\prime} / S_{2}{ }^{\prime}\right) \frac{d \phi}{d \theta}$. Calculated by means of this formula, in which $S_{1}{ }^{\prime} / S_{2}{ }^{\prime}$ is assumed to be unity and $\frac{d \phi_{0}}{d \theta}$ is obtained from the graph, the rate of change of twist $\frac{d \psi_{0}}{d \theta}$ is 0.020 degree per ${ }^{\circ} \mathrm{C}$.

To show that this rate of change of deflection at zero angular deflection actually occurs the test spring was disengaged from the clamp and its deflection measured as the temperature was varied. 
The following results were obtained, which are in satisfactory agreement with value given above.

\begin{tabular}{|c|c|}
\hline $\begin{array}{c}\text { Tempera- } \\
\text { ture of the } \\
\text { spring }\end{array}$ & $\begin{array}{c}\text { Degree of } \\
\text { twist per } \\
{ }^{\circ} \mathrm{C} .\end{array}$ \\
\hline${ }^{\circ}{ }^{\circ}$. & \\
+15 & 0.022 \\
+8 & .022 \\
-16 & .021 \\
-24 & .021 \\
\hline
\end{tabular}

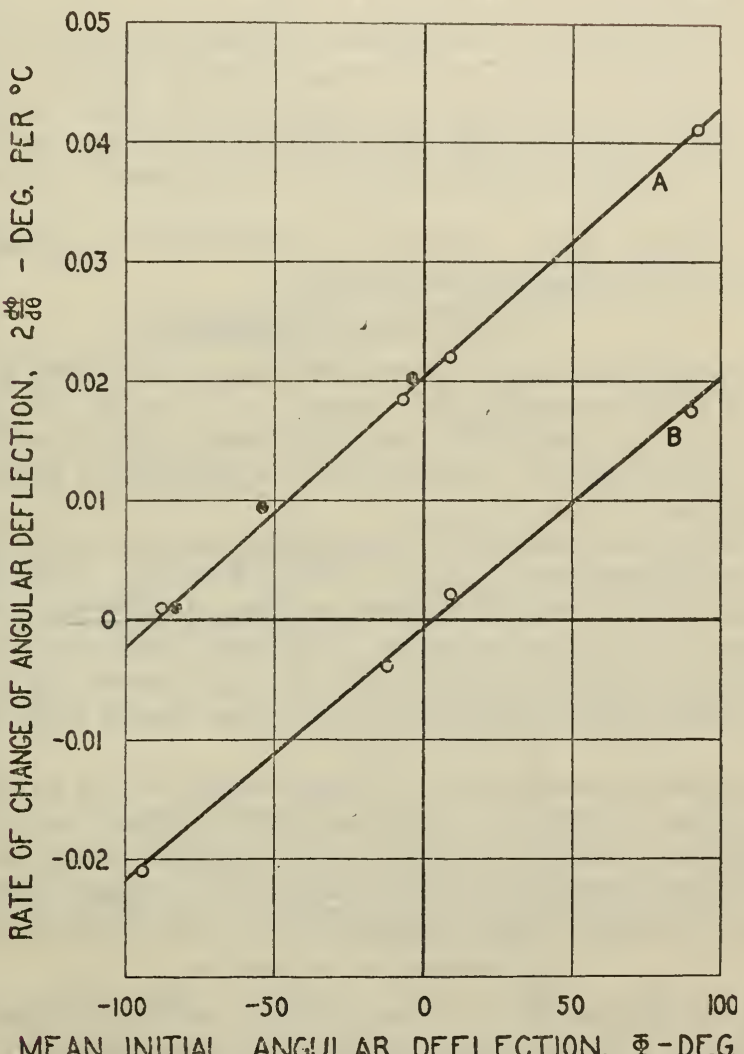

FIGURE 12-Relation of twice the rate of change in angular deflection $\frac{2 d \phi}{d \theta}$ with temperature to the mean initial angular deflection $\Phi$ of the springs No. 5 a and $5 b$

Data represented by the line $A$ were obtained with the springs shaped from the oil-tempered wire. The test spring shows twist at zero deformation. Data represented by the line $B$ were obtained with the springs annealed after shaping

To show that $\frac{d \psi_{0}}{d \theta}$ is substantially constant for all values of the deflection of the spring the following experiment was performed. The auxiliary and test springs were initially twisted in opposite directions by amounts $\Phi_{1}=-83^{\circ}$ and $\Phi_{2}=+83^{\circ}$ and clamped. The tempera- 
tures of both of the springs were varied as a unit starting from a common temperature. There was a consequent twist of $0.020^{\circ}$ per ${ }^{\circ} \mathrm{C}$. which is in good agreement with the results previously obtained.

The deflection with temperature at the initial zero angular deflection is relatively large for steel springs which were not heat treated after being wound.

For springs heat treated after winding this effect was practically zero which is shown in a striking way by curve $B$ in Figure 12 which represents the data obtained after annealing spring No. 5a. The fact that $\frac{d \psi_{0}}{d \theta}$ is here practically zero suggests that this deflection with temperature results from the stressed condition of the spring material. Probably it is due not so much to a modification during a temperature cycle of the internal stresses introduced by working the material, as to the fact that the material has additional changes in deflection in the internally stressed portions due to the effect of temperature on the modulus.

Springs shaped from nonferrous hard-drawn materials show a similar effect but smaller in magnitude.

\section{(d) EXPERIMENTAL RESULTS}

The values of the temperature coefficient $e$ of Young's modulus of elasticity at $0^{\circ} \mathrm{C}$. are given in Table 3 . Values of the ratio $e_{25} / e_{-25}$ of the temperature coefficients at $+25^{\circ}$ and $-25^{\circ} \mathrm{C}$. and the difference $m_{0}-e_{0}$ between the temperature coefficients of the two moduli are also given.

The temperature coefficient $e_{0}$ is also the average value of the coefficient in the temperature range $-50^{\circ}$ to $+50^{\circ} \mathrm{C}$. The ratio $e_{25} / e_{-25}$ is a measure of the variation of the coefficient with temperature.

No values of the temperature coefficient were derived from the data obtained on stainless steel spring No. $23 \mathrm{~b}$, since, due to the anomalous behavior which is discussed later, these would be of little significance.

The temperature coefficient $e_{\mathrm{o}}$ was not obtained for modulvar owing to the excessive vibration of the small spring which had to be used.

The maximum bending stresses at the maximum twist of the springs were in all cases considerably less than those in shear. Consequently, the stresses were in all cases below those at the elastic limit.

\section{(e) ACCURACY OF RESULTS}

The sources of error in the determination of the temperature coefficient of Young's modulus are (1) in the measurement of the mean initial deflection of the auxiliary and test springs and (2) in the measurement of temperature of the springs. For the great majority of the springs the error in determining the initial deflection was within 1 per cent and in all cases the error in the temperature was within $1^{\circ} \mathrm{C}$. Thus, not considering the possible error in the value of the thermal coefficient of expansion, the error in the coefficient does not exceed 2 per cent.

The error in the ratio of the temperature coefficient at $+25^{\circ} \mathrm{C}$. to that at $-25^{\circ} \mathrm{C}$. is principally due to the difference in the angular deflection of the spring for decreasing and increasing temperatures. This difference in deflection was very much less than in the case of the experiments to determine the temperature coefficient of the modulus of rigidity and therefore the errors are substantially less. 


\section{DISCUSSION}

\section{ANOMALOUS BEHAVIOR OF STAINLESS STEEL}

The behavior of annealed stainless steel (KA2) spring No. 23b containing 0.05 per cent carbon, is very unusual compared with those

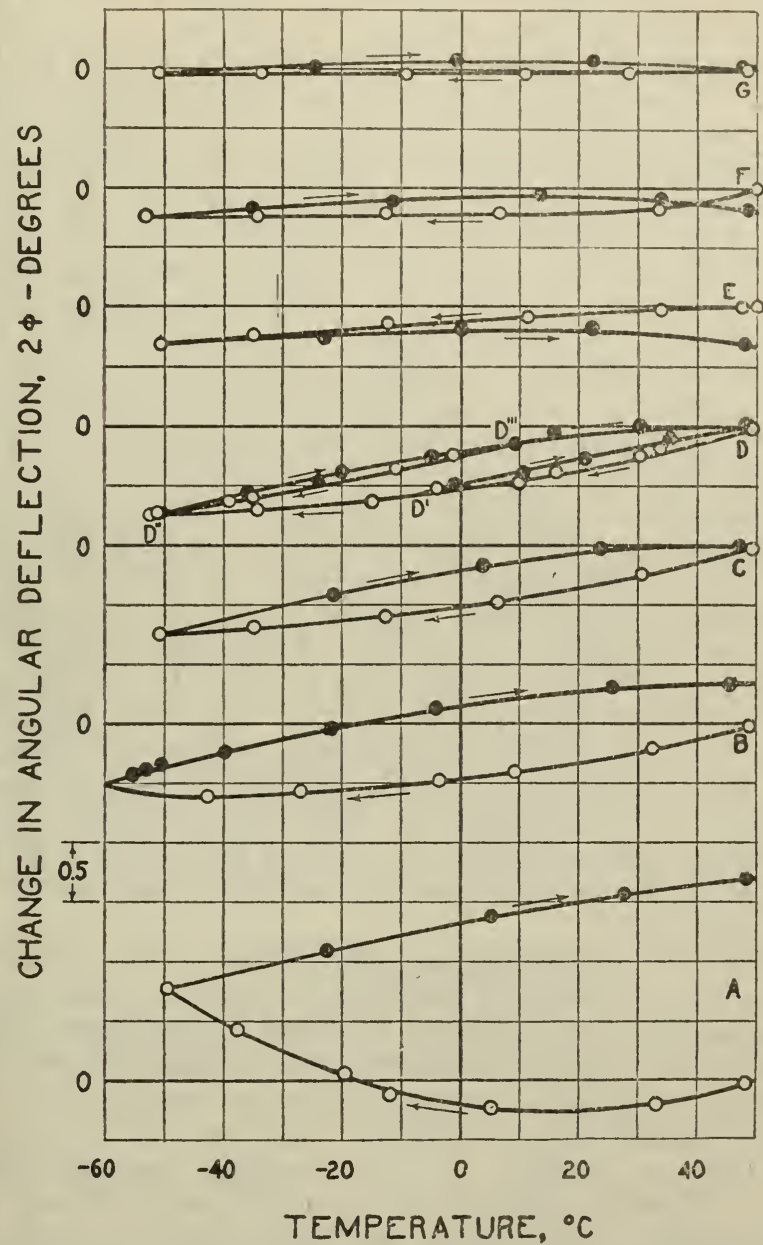

FIGURE 13.-Effect of temperature on the angular deflection of a spring (No. 23b) of annealed stainless steel

Each group of curves $A, B$, and $C$ and $E, F$, and $G$ are the results of the first, second, and fifth test for an initial angular deflection $(\Phi)$ of 41.6 for the first group and $11.4^{\circ}$ of arc for the second. Curves $D$ were obtained after three temperature cycles for an initial angular deflection of $41.6^{\circ}$, and shows the spring to be in the cyclic state. The open circles represent observations made in the decreasing temperature part and the solid circles in the increasing temperature part of the cycle.

of other materials. The results of some of the tests are shown in Figure 13.

The change in angular deflection as a function of the temperature is given in Figure 13. Before obtaining these data the springs were given an average angular deflection of $42^{\circ}$ and the differential drift 
noted which after a period of time became less than $0.02^{\circ}$ per hour. The test spring was then subjected to the usual temperature cycle and the change in deflection measured, obtaining the values shown in curve $A$ (fig. 13). As the temperature was decreased from $+50^{\circ} \mathrm{C}$. the modulus first increases and then decreases, while during the returning half of the temperature cycle $\left(-50^{\circ}\right.$ to $+50^{\circ}$ C. $)$ the rate of change of the modulus was much more constant. At the end of this temperature cycle the metal had a lower value of the modulus than at the start. This difference in modulus became less and less for each succeeding temperature cycle, becoming zero after the fifth cycle.

As has been previously stated (equation (14) the temperature coefficient at any temperature is in linear relation to the slope of this curve from which it is evident by inspection that the coefficient of Young's modulus departs considerably from a constant value.

Curve $B$ of Figure 13 gives the data for the second temperature cycle and curve $C$ that for the fifth. Notice in the latter curve that the temperature coefficient varies with temperature and also that the modulus has different values at a given temperature, except at $+50^{\circ}$ and $-50^{\circ} \mathrm{C}$., in the two branches of the temperature cycle. Further tests showed that this appears to be the cyclic state of the material for this temperature range and deflection. After making test No. 5, curve $C$, the springs were allowed to untwist and then were again retwisted to the same angular deflection. It was now necessary to pass the spring through three temperature cycles to establish again the cyclic state (tests Nos. 6, 7, and 8). In test No. 10 the temperature cycle was from $+50^{\circ}$ to $+5^{\circ}$ and back to $+50^{\circ} \mathrm{C}$., the data for which are shown by curve $D D^{\prime}$ in Figure 13. This was repeated in test No. 11. In test No. 12 the temperature cycles were from $+50^{\circ}$ to $-50^{\circ}$ to $+10^{\circ}$ to $-50^{\circ}$ to $+50^{\circ}$ C., data for which are shown by the curves $D D^{\prime \prime} D^{\prime \prime}$ ' $D$ in Figure 13 . This figure clearly shows that a true cyclic state was established. Curves $E, F$, and $G$ in Figure 13, give the results of the first, second, and fifth tests when the initial deflection was $11.4^{\circ}$.

The behavior of this material was similar in the experiments for determining the coefficient of the rigidity modulus although a slightly different procedure was followed in these experiments. In the first temperature cycle a curve similar in form to that of curve $A$ (fig. 13) was obtained. After this test the spring was subjected to three successive temperature cycles $\left(+50^{\circ}\right.$ to $-50^{\circ}$ to $+50^{\circ}$ C. $)$ in as short a period of time as possible, without making measurements of the deflection. During the next cycle measurements showed the spring to be in the same cyclic state, as shown in curve $C$ of Figure 13 which was obtained as a result of tests which took a definitely much longer time to make. Since the cyclic state was obtained independently of time it is concluded that the behaviour is mainly an effect due to change in the constitution with temperature and not of elastic afterworking.

The effect was obtained only to a slight degree with stainless steel spring No. 24b which is in agreement with the negative result of cold treatment obtained by Luerssen and Green ${ }^{2}$ with a sample of approximately the same composition, especially as to the carbon content. The difference in behavior of springs $23 \mathrm{~b}$ and $24 \mathrm{~b}$ appears to be

\footnotetext{
2 G. V. Luerssen and O. V. Green, Trans. Am. Soc. Steel Treat., vol. 19, p. 501, 1932.
} 
caused by the difference in the carbon content, respectively, 0.05 and 0.14 per cent, which seems to be reasonable according to the work of Krivobok and Gensamer. ${ }^{3}$

\section{RELATIVE VALUES OF THE TEMPERATURE COEFFICIENTS}

An inspection of Table 3 shows that, of the pure metals, tungsten has the smallest temperature coefficient and also the smallest coefficient of thermal expansion. This is in accordance with the modification of Wertheim's law given by Andrews, ${ }^{4}$ which includes as a corollary, that for pure metals, a small temperature coefficient of elasticity and a small thermal coefficient of expansion are associated. The relatively large differences in the coefficients $m$ and $e$ for tungsten may be due to the fact that the crystal structure of the wires was fibrous rather than isotropic.

With the exception of stainless steel KA2, elinvar, and modulvar, it is seen that the temperature coefficients of the steels vary within a rather small range, from 19 to $27 \times 10^{-5}$.

Modulvar, which has practically the same composition as invar, is known ${ }^{5}$ to have a large positive coefficient which is confirmed by the present results. The values for the sample of elinvar were rather higher than expected. ${ }^{5}$ However, the material is known to require careful heat treatment to obtain the low coefficient. It was not heat treated after the cold work incidental in forming the spring.

The two stainless steels KA2, with carbon contents of 0.14 and 0.05 per cent, have temperature coefficients of the elastic moduli which are considerably higher than those of the other steels. These steels also have higher thermal coefficients of expansion.

Of the group of nonferrous materials, duralumin has the largest temperature coefficient and Monel metal the smallest. The coefficients of the nickel silvers, brass, phosphor bronze, and beryllium bronze differ but littel from those found for copper by other investigators.

\section{VARIATION OF THE TEMPERATURE COEFFICIENTS OF THE MODULI WITH TEMPERATURE}

The coefficients $m_{0}$ and $e_{0}$ given in Table 3 are also with but negligible error the average values of the coefficients for the temperature interval $-50^{\circ}$ to $+50^{\circ} \mathrm{C}$. Although the values of the ratios $\frac{m_{25}}{m_{-25}}$ and $\frac{e_{25}}{e_{-25}}$ are open to question in some cases, they are even in these cases of value as an indication of the variation of the temperature coefficients with temperature. Very roughly, but sufficiently accurate for many purposes, the ratio

$$
\frac{m_{0}}{m_{-50}}=\frac{m_{50}}{m_{0}}=\frac{m_{25}}{m_{-25}}
$$

and similarly for the coefficients of Young's modulus.

The coefficients in all cases increase in absolute value with increasing temperature. For the materials, phosphor bronze, nickel silver, and

V. N. Krivobok and M. Gensamer, Trans. Am. Inst. Min. and Metall. Eng., Iron and Steel Div., p. 325,1931 .

J. P. Andrews, Phil. Mag., series 6, vol. 50, p. 665, 1925.

- P. Chevenard, Travaux et Memoires de Bur. Int. des Poid et Mes., vol. 17, 1927. 
brass, all containing copper, the rate of increase is not as large as in steel, duralumin, and Monel metal. For some of the stainless steels the coefficients appear to increase at a greater rate than for other steels.

For high-carbon steels (spring Nos. 6a, 6b, 13a, and 13b) the average value

$$
\frac{m_{25}}{m_{-25}}=1.13 \text { and } \frac{e_{25}}{e_{-25}}=1.11
$$

Tomlinson's expression ${ }^{6}$ for the relation between the rigidity modulus of iron and temperature for the temperature range $0^{\circ}$ to $100^{\circ} \mathrm{C}$. gives 1.11 for the above ratio of the torsion moduli when extrapolated to $-25^{\circ}$ C. Dadourian's expression ${ }^{7}$ for the relation of Young's modulus of steel and temperature for temperatures above $0^{\circ} \mathrm{C}$., gives 1.29 for the ratio of the modulus at $+25^{\circ} \mathrm{C}$. to that at $-25^{\circ} \mathrm{C}$.

\section{TEMPERATURE COEFFICIENT OF POISSON'S RATIO}

Grüneisen ${ }^{8}$ in an important paper on the compressibility of isotropic elastic materials has deduced the relations

$$
\begin{aligned}
& \text { I. } m>e>\gamma \\
& \text { II. } m-e=\frac{G \eta}{3}(e-\gamma) \\
& \text { III. } \frac{1}{\sigma} \frac{d \sigma}{d \theta}=\frac{1+\sigma}{\sigma}(m-e)
\end{aligned}
$$

where $\sigma$ is Poisson's ratio, $\eta$ the compressibility and the thermal coefficient of compressibility. The first relation is based on the assumption that compressibility, as well as Poisson's ratio, increases with temperature. The second and third relations result from the isotropic character of elastic materials.

The value of the quantity $\frac{G \eta}{3}$ is known to be a small fraction, different for various materials, but always lying between the limits one-sixth and one-twelfth. The above relations are very useful as they afford us a means of knowing how large the difference between the two temperature coefficients of the moduli can be.

When, with the first Grüneisen relation in mind, the two coefficients $m$ and $e$ are compared it is found that, except in a few cases, $m-e$ is positive, and also that the difference is larger for nonferrous material than for the steels.

Restricting our consideration to the steels, it may be inferred, because of Grüneisen's second relation, that either the thermal coefficient of Poisson's ratio for steels at $0^{\circ} \mathrm{C}$. is zero or a very small quantity. Bock's ${ }^{9}$ results on the direct determination of Poisson's ratio of hardened English steel by Kirchoff's method and for a temperature

\footnotetext{
- H. Tornlinson, Proc. Roy. Soc., vol. 40, p. 343, 1886.

7 H. M. Dadourian, Phil. Mag., vol. 42, p. 442, 1921.

E. Grüneisen, Ann. d. Phys., vol. 33 (338), p. 1239, 1910.

A. Bock, Wied. Ann., vol. 52, p. 609, 1894.
} 
range, $20^{\circ}$ to $150^{\circ} \mathrm{C}$., may be represented by the following expression-

$$
1,000 \sigma=255.6+0.019 \theta+0.00009 \theta^{2}
$$

from which we find for the thermal coefficient of Poisson's ratio at $0^{\circ} \mathrm{C}$.

$$
\frac{1}{\sigma} \frac{d \sigma}{d \theta}=7 \times 10^{-5}
$$

Using Grüneisen's third relation this gives the value $2 \times 10^{-5}$ for the difference $m-e$ which agrees with the results for high-carbon steels given in Table 3.

Katzenelsohn, ${ }^{10}$ Schaefer, ${ }^{11}$ and Angenheister, ${ }^{12}$ among the earlier observers, have determined both of the quantities $m$ and $e$ from experiments made on the same specimen. Although they find $m$ to be larger than $e$, Grüneisen has remarked that with these observers the difference $m-e$ was too large to be compatible with his second relation, particularly for results on materials of high melting points. Goens, ${ }^{13}$ among recent observers, has determined these quantities for aluminum and brass by a new method from the same specimen of each material. The difference $m-e$ obtained by him for brass is of the same order of magnitude as that in the present investigation.

\section{EFFECT OF HEAT TREATMENT ON THE TEMPERATURE COEFFI- CIENTS OF THE ELASTIC MODULI}

The coefficients of the elastic moduli of high-carbon steels (springs $6 \mathrm{a}, 6 \mathrm{~b}, 13 \mathrm{a}$, and $13 \mathrm{~b}$, Table 3 ) are affected very definitely by heat treatment. The coefficients of the annealed specimens are about 20 per cent less than those for the tempered specimens. It is significant that annealing brings the value of the coefficients very near to the value found by other experimenters for iron. Coefficient $e_{0}$ for iron was found by Geons ${ }^{14}$ to be $-21.3 \times 10^{-5}$; by Katzenelsohn ${ }^{15}-22.3 \times 10^{-5}$; by Thomas ${ }^{16}-19.4 \times 10^{-5}$. For iron Tomlinson ${ }^{17}$ found $m_{0}$ to be $-24.4 \times 10^{-5}$; Guye and Fredericksz ${ }^{18}-21.3 \times 10^{-5}$.

In alloys steels, however, the effect of heat treatment is not very definite; differences that were found were of the same order as the errors of experimentation. The results for chromium-vanadium steel do not contradict those of Brombacher and Melton ${ }^{19}$; the results on nickel steel agree with those of Kimball and Lovell. ${ }^{20}$

Among the nonferrous materials one spring of the nickel-silver group was tested in the as-received condition and also after annealing. Annealing produced, as is seen from the Table 3, a decrease of about 10 per cent in the value of the coefficients, which is a decrease of the same order as found by Brombacher and Melton. In the case of Monel metal the decrease was less than that found for nickel silver.

\footnotetext{
${ }^{10}$ N. Katzenelsohn, Inn. Diss. (Berlin), 1887

11 C. Schaeffer, Ann. d. Phys., vol. 5 (310), p. 220, 1901

12 G. Angenheister, Ann. d. Phys., vol. 11 (316), p. 188, 1903.

$11 \mathrm{E}$. Goons, Ann. d. Phys., vol. 4 (396), p. 733, 1930.

16 See footnote 13 , p. 319 .

is See footnote 10, p. 319

16 Paul A. Thomas, Dissertation, (Jena), 1899

17 See footnote 6, p. 318.

is C. E. Guye and V. Fredericksz, Compt. Rend., vol. 149, p. 1066, 1909

10 See lootnote 1, p. 290.

20 A. L. Kimball, jr., and D. E. Lovell, Phys. Rev., vol. 26, p. 121, 1925. $156547-33-3$
} 


\section{CONCLUSIONS}

The temperature coefficient of the modulus of rigidity and of the modulus of elasticity of a number of metals and alloys have been determined in the temperature range $-50^{\circ}$ to $+50^{\circ} \mathrm{C}$. The coefficients were obtained in so far as possible on each material in the condition of heat treatment or cold work most suitable for its use as a spring or diaphragm and also in the annealed condition. The experimental results are presented in Table 3.

It is shown that Grüneisen's three relations between the temperature coefficients and Poisson's ratio were in general confirmed by these data.

The temperature coefficients were found, for the most part, to be dependent, to a significant extent, on the heat treatment and cold work of the material.

Except for tungsten the percentage difference in the two temperature coefficients was sufficiently small so that for practical purposes they may be taken as equal.

The coefficients, in general, varied with temperature. The average value for the temperature interval $-50^{\circ}$ to $50^{\circ} \mathrm{C}$. is that for $0^{\circ} \mathrm{C}$. given in Table 3.

The coefficients are independent of external stress within the maximum stress at which the springs were tested.

\section{ACKNOWLEDGMENTS}

The Aluminum Co. of America, the American Steel \& Wire Co., the International Nickel Co., the Seymour Manufacturing Co., the Phosphor Bronze Smelting Co., the Beryllium Development Corporation, the Wallace Barnes Co., and the Cuyahoga Steel \& Wire Co. cooperated by furnishing special materials for use in this investigation.

We are greatly indebted to Dr. W. G. Brombacher for valuable assistance, especially in the preparation of the manuscript, and to F. Cordero for his suggestions in the design of the apparatus.

Washington, September 10, 1932. 